\title{
Foundations of the Goldilocks Economy: Supply Shocks and the Time-Varying NAIRU
}

The AmERICAN ECONOMY of the mid-1990s has been a source of envy for the world and of puzzlement for macroeconomists. The civilian unemployment rate has remained below 5 percent for one year and below 6 percent for almost four years. Despite near universal forecasts in 1994 of accelerating inflation that would accompany a dip of the unemployment rate below 6 percent, inflation actually decelerated significantly between 1994 and 1998. This benign outcome for inflation stands in contrast to the significant acceleration that occurred when unemployment last dipped below 6 percent, in the late 1980s. ${ }^{1}$

The failure of inflation to accelerate allowed the Federal Reserve to avoid raising short-term interest rates after early 1997, and even to lower them in late 1998. Freed from the restraint of restrictive monetary policy that had choked earlier expansions, and with its fires stoked by the lowest medium-term and long-term nominal interest rates in three decades, the economy charged ahead and achieved a state of high

This research is supported by the National Science Foundation. I am grateful to William Nordhaus and to participants of the Brookings Panel meeting for helpful comments. Christian Ehemann and Steven Landefeld were invaluable, both in providing data and helping me to understand them. Aarti Dhupelia, Tominori Ishikawa, and Stuart Gurrea provided excellent research assistance. Above all, I am greatly indebted to James Stock for his role in developing the methodology adopted in this paper, and for his instant and insightful responses to my endless queries about how to merge his new techniques with my traditional specification of the Phillips curve.

1. The four-quarter rate of change of the chain-weighted GDP deflator decelerated from 2.5 percent in 1994:3 to 1.0 percent in 1998:2, in contrast to its acceleration from 3.1 percent in 1987:3 to 4.2 percent in 1990:2 (see table 1 below). 
growth-noninflationary bliss that some have dubbed the "Goldilocks economy" (neither too hot nor too cold, but just right). Low interest rates and low inflation combined to propel the American stock market to valuation levels without precedent, along the way creating \$10 trillion of wealth in barely four years, and most of this wealth was still intact after the market correction in the summer and fall of 1998. Overcome with enthusiasm, one distinguished economist gushed, "This expansion will run forever.", 2

While some observers have attributed the miracle economy to the Fed's brilliant monetary policy, it is clear that the true heroine of the drama is the deceleration of inflation, and the basic challenge for economists is to explain that deceleration. ${ }^{3}$ Proposed explanations can be divided among three groups. ${ }^{4}$ The first view announces a revolution and the arrival of a "new economy": the rapid growth of production of high-technology products, many of which enjoy continuing declines in prices, has rendered obsolete previous capacity constraints associated with the Phillips curve, while globalization has provided low-technology products in infinite quantity at ever-lower prices. ${ }^{5}$ The second, which also denounces the Phillips curve view, argues on econometric grounds that the NAIRU (or "nonaccelerating inflation"' rate of unemployment), natural rate hypothesis, and short-run Phillips curve have never existed, even prior to $1990 .^{6}$

2. Rudiger Dornbusch, “Growth Forever,' Wall Street Journal, July 30, 1998, editorial page.

3. Compare the two-year period ending in 1998:2 with the last two years of the previous expansion, ending in 1990:2. The annual rate of nominal GDP growth was considerably slower in the recent period than in the earlier period ( 5.0 percent compared with 7.0 percent), but inflation was so much lower ( 1.5 percent compared with 4.3 percent) that the annual rate of real GDP growth was higher ( 3.5 percent compared with 2.7 percent). Correspondingly, the unemployment rate fell by more over the most recent two-year period, from 5.4 to 4.4 percent, than the slight decline from 5.5 to 5.3 percent observed in the earlier two-year period.

4. While the present account places primary emphasis on inflation behavior, there is also an independent view of monetary policy that predicts steady expansion based on the long-term bond market acting as an automatic stabilizer, thus making discretionary action by the Fed unnecessary; see Gene Koretz, "A Golden Age of Steady Growth?", Business Week, March 10, 1997, p. 22.

5. The new economy advocates are led by Edward Yardeni, chief economist of Deutsche Morgan Grenfell. A skeptical view is provided in "Too Triumphalist by Half," Economist, April 25, 1998, p. 29.

6. A leading proponent of this view is my colleague at Northwestern University, 
The third view defends the natural rate version of the Phillips curve and explains recent events as consistent with a decline in the NAIRU. Using techniques developed by Douglas Staiger, James Stock, and Mark Watson, I have elsewhere provided estimates that the NAIRU in the United States declined by a full percentage point between the mid1980s and mid-1990s. In this interpretation, inflation accelerated in 1987-89 but not in 1995-98, because the actual unemployment rate was significantly below the NAIRU in the previous episode but not in the recent period. ${ }^{7}$

The first round of papers on the time-varying NAIRU (hereafter TVNAIRU) in 1997 identified the phenomenon of the declining NAIRU in the 1990s but did not explain it. This paper takes the next step. The list of candidate explanations is long and can be roughly grouped into three sets: a first, general group of explanations not directly related to wage or price behavior; a second group related to wage behavior; and a third related to price behavior.

General candidates include vague references to the new economy or "a mysterious X factor that Alan Greenspan believes is boosting the economy." 8 These hypotheses run aground on the failure of measured productivity growth to accelerate significantly in the 1990 s. ${ }^{9}$ Another general candidate is the set of international crises-in Asia, Russia, Latin America, and elsewhere-which have created a flight to quality

Robert Eisner. For instance, see his article "The Economy is Booming. So Why Are Economists Glum?', Wall Street Journal, July 29, 1998, editorial page. See also Levy (1997).

7. Staiger, Stock, and Watson (1997); Gordon (1997). The time series for the timevarying NAIRU created by Staiger, Stock, and Watson is very similar to mine when the same definition of inflation is used. See also Stock (1998); Stock and Watson (1998b).

8. Andy Serwer, 'The 'X Factor'? It's My Pal Bedford,' Fortune, August 17, 1998, p. 233.

9. Since the task is to explain the officially measured deceleration of inflation, it is the officially measured rate of productivity growth that matters; any suspected measurement error would reduce the inflation rate and raise the rate of productivity growth by exactly the same amount for any specified sector of the economy-for example, the nonfarm private business sector-and thus would not contribute an explanation for the measured deceleration of inflation. Supporting the view that the officially measured rate of productivity growth has not accelerated, the private nonfarm business productivity trend used below to create the productivity deviation variable and also to compute trend unit labor cost registers an annualized rate of increase over 1987-98 of only 1.06 percent per year. Over the shorter six-year period ending in 1998:2, the annualized growth rate is 1.11 percent per year. As interpreted by my detrending procedure, the level of productivity was above trend by 0.5 percent in 1992:2 and by 0.9 percent in 1998:2 
and the American "safe haven" in world capital markets, resulting in the appreciation of the dollar and the reduction of both interest rates and import prices in the United States.

Hypotheses involving wage behavior point to weak labor unions, a secular decline in the real minimum wage, "heightened job insecurity," and falling benefit costs due primarily to the revolution in medical care through the development of health maintenance organizations (HMOs).

Hypotheses involving price behavior are the main focus of this paper, which suggests that the low inflation of the mid-1990s resulted from the confluence of no fewer than five beneficial supply shocks, each working to reduce the inflation rate consistent with any given unemployment rate. Two of these beneficial shocks are the familiar pair-changes in real food and energy prices and in real import prices-that working in reverse played such a large role in creating the twin peaks of unemployment and inflation in 1974-75 and 1979-81, and have now helped to create an inflation-unemployment valley. The other three are of more recent origin: a sharp increase in the rate of deflation of real computer prices, a sharp reduction in the rate of inflation in real medical care prices, and a reduction in measured inflation relative to true inflation achieved by improvements in the measurement of official price indexes.

Three of these beneficial supply shocks are complementary with others cited above. The flight of capital to a safe haven explains much of the decline in real import prices. The role of computer prices provides a quantifiable measure of the role of at least part of the new economy. And the HMO-driven decline in real medical care inflation is the flip side of the decline in the rate of change of fringe benefits that has held down the growth rate of employee compensation.

Thus far, I have characterized the major surprise in the Goldilocks economy as the low rate of inflation given the low rate of unemployment, and indeed, this has been the focus of the media as well. But combined with that surprise there have been several central macroeconomic relationships that are not surprises, and the task of explaining the contrast between the surprises and "nonsurprises" creates a complex and subtle interpretation of the Goldilocks economy. While inflation has been low given the behavior of unemployment, inflation has not been surprisingly low given the behavior of an alternative measure of the economy's tightness: the rate of capacity utilization.

A parallel phenomenon is that the behavior of wages has not been 
surprising given unemployment. Unemployment has been low and, as would be predicted by the standard Phillips curve, wage rates have accelerated substantially between 1994 and 1998. Thus creating a twoby-two matrix consisting of two inflation measures, price changes and wage changes, and two measures of economic tightness, the capacity utilization rate and the unemployment rate, gives two surprises-low inflation despite low unemployment and accelerating wages despite relatively low utilization-and two nonsurprises-accelerating wages responding to low unemployment and low inflation responding to relatively low capacity utilization. Stated another way, the real questions about the Goldilocks economy are why inflation has been so low relative to changes in wages and why the unemployment rate has declined when utilization has not increased. ${ }^{10}$

The aspect of these puzzles involving the relation between price and wage changes reveals a limitation of previous work by myself and others on the TV-NAIRU. This research has focused entirely on equations in which inflation is explained by lagged inflation, the unemployment gap, and various supply shocks, paying no attention at all to wages. This paper is the first in the literature to devote parallel attention to wages and prices, and also to consider mutual feedback between wages and prices. Can the inflation rate be explained entirely by lagged inflation and other variables, or does feedback from wage behavior play a role? Can wage changes be explained entirely by lagged wage changes and other variables, or does feedback from price behavior play a role?

I begin with a brief review of my traditional inflation model and extend it to provide a simple method of estimating feedback between wage and price changes. In the following section I look briefly at the data that document the deceleration of inflation and at the quite different behavior of wage indexes that include or exclude benefits, and contrast wage and price behavior in 1994-98 with that in 1987-90. I then develop quantitative measures of the extent to which the behavior of price inflation in 1993-98 represents a surprise.

The next section quantifies the roles of the traditional import price and food-energy price supply shocks in the 1990s. In the following section, I assess the roles of computers, medical care, and measurement

10. I owe this characterization to James Stock's comments on the meeting draft of the paper. 
changes in price changes by stripping these effects from the official GDP and personal consumption expenditure (PCE) deflators. I then estimate new TV-NAIRUs to demonstrate the roles of these three more recent supply shocks. In the next section I review tests of feedback among wage and price equations and provide alternative estimates of the TV-NAIRU taking these estimates into account. Finally, I summarize what is known about the likely behavior of both the older and the more recent supply shocks over the next few years, and the implications for the evolution of inflation and of the TV-NAIRU.

\section{Modeling Inflation, the TV-NAIRU, and Mutual Wage-Price Feedback}

The Phillips curve has become a generic term for any relationship between the rate of change of a nominal price or wage and the level of a real indicator of the intensity of demand in the economy, such as the unemployment rate. In the 1970 s the simple Phillips relation was amended by incorporating supply shocks and a zero long-run trade-off. What emerged was an interpretation of the Phillips curve that I have called the triangle model of inflation, in reference to the three basic determinants of the inflation rate: inertia, demand, and supply. ${ }^{11}$

For example, a general specification of this framework would be

$$
p_{t}=a(L) p_{t-1}+b(L) D_{t}+c(L) z_{t}+e_{t},
$$

where lower-case letters designate first differences of logarithms, upper-case letters designate logarithms of levels, and $L$ is a polynomial in the lag operator. The dependent variable $p_{t}$ is the inflation rate. Inertia is conveyed by the lagged rate of inflation $p_{t-1}$. $D_{t}$ is an index of excess demand, normalized so that $D_{t}=0$ indicates the absence of excess demand; $z_{t}$ is a vector of supply shock variables, normalized so that

11. Gordon (1977, 1982) and Gordon and King (1982) develop a model of the inflation process driven by these three factors. The term "triangle model" was first used in Gordon (1983). The origins of the triangle model and additional perspective are provided in Gordon (1997). Stock (1998, p. 3) cites Gordon (1982) as the source of the framework that Stock, Staiger, and Watson have used in estimating the TV-NAIRU. 
$z_{t}=0$ indicates an absence of supply shocks; and $e_{t}$ is a serially uncorrelated error term. ${ }^{12}$

Usually, equation 1 will include several lags of past inflation rates, reflecting the influence of several past years of inflation behavior on current price-setting, through some combination of expectation formation and overlapping wage and price contracts. If the sum of the coefficients on these lagged inflation values equals unity, there is a "natural rate" of the demand variable $\left(D_{t}^{N}\right)$ consistent with a constant rate of inflation. ${ }^{13}$ Subsequently, I provide alternative versions of equation 1 that explain wage changes, with and without two-way feedback between prices and wages. The basic equations estimated in this paper use current and lagged values of the unemployment gap as a proxy for the excess demand parameter $D_{t}$, where the unemployment gap is defined as the difference between the actual rate of unemployment and the natural rate, and the natural rate is allowed to vary over time. Use of the unemployment rate as a predictor of inflation can be justified, for example, by the work of Robert King and Watson, who find that unemployment causes inflation in the Granger-causation sense, by preceding it in time. ${ }^{14}$ Alternatively, the capacity utilization rate is used as a proxy for the excess demand parameter $D_{t}$, and the natural rate of the capacity utilization rate is also allowed to vary through time.

The structure of the triangle model, with its distinction between demand and supply shocks, suggests a particular conception of the NAIRU. The standard concept is the unemployment rate that is consistent with steady inflation in the absence of supply shocks. To put it

12. The theory of real output, inflation, and policy responses to supply shocks was developed independently by Gordon (1975) and Phelps (1978), and is integrated and summarized in Gordon (1984).

13. While the estimated sum of the coefficients on lagged inflation is usually roughly equal to unity, that sum must be constrained to be exactly unity for a meaningful "natural rate" of the demand variable to be calculated.

14. See King and Watson (1994). Inflation depends on both the level of and change in the demand variable. I first noted the importance of the rate of change effect in Gordon (1977, pp. 270-71). The rate of change effect is automatically allowed to enter as long as the gap variable is entered with more than one lag; in other words, if the gap variable is entered as, say, the current value and one lagged value, this formulation contains precisely the same information as entering the current level and change from the previous period. The change variable is incorporated in the present paper, as in previous papers, by including the current and four lagged values of the unemployment rate; the zig-zag in the current and lagged coefficients reflects the change effect, whereas the significant sum of coefficients reflects the level effect. 
another way, if the inflation rate suddenly exhibits a spike that is entirely explained by the $z_{t}$ supply shock variables in equation 1 , the standard conception of the NAIRU measures the unemployment rate that would be compatible with steady inflation in the absence of those supply shocks. Without this qualification, the NAIRU would jump around as supply shocks came and went, which is not what most economists are trying to convey when they speak of the natural rate of unemployment.

\section{Allowing the NAIRU to Vary over Time}

The estimation of the time-varying NAIRU $\left(U^{N}\right)$ combines inflation equation 1, with the unemployment gap serving as the proxy for excess demand, and a second equation that explicitly allows the NAIRU to vary with time:

$$
\begin{gathered}
p_{t}=a(L) p_{t-1}+b(L)\left(U_{t}-U_{t}^{N}\right)+c(L) z_{t}+\epsilon_{t}, \\
U_{t}^{N}=U_{t-1}^{N}+\eta_{t}, \quad E \eta_{t}=0, \quad \operatorname{var}\left(\eta_{t}\right)=\tau^{2} .
\end{gathered}
$$

When $\tau$ in equation 3 is equal to zero the natural rate is constant, and when it is positive the model allows the NAIRU to vary by a limited amount each quarter. If there was no limit on the ability of the NAIRU to vary each time period, the time-varying NAIRU would jump up and down and soak up all the residual variation in the inflation equation.

\section{The Interaction of Wage and Price Behavior}

Recent discussions of the time-varying NAIRU have focused on equations explaining price inflation, because this concept of inflation is the most directly relevant to monetary policy. However, ever since Keynes's General Theory, the rate of change of wages has been believed to play a central role in aggregate supply behavior. One direct indicator of the role of wages in the inflation process is provided by labor's share in national income. The change in labor's share $\left(s_{t}\right)$ is by definition equal to the growth rate of the real wage $\left(w_{t}-p_{t}\right)$ minus the growth rate of labor's average product $\left(\theta_{t}\right)$ :

$$
s_{t}=w_{t}-\theta_{t}-p_{t} .
$$

It can be shown that changes in labor's share become a source of "cost 
push" that is on an equal footing with any other type of supply shock; an increase in labor's share pushes upward on the rate of inflation at any given level of the unemployment gap. ${ }^{15}$

The well-known stability of labor's share in the United States since the early 1970s suggests that wage behavior has not played much of an independent role in the inflation process. Nevertheless, it is informative to create estimates of the NAIRU corresponding to the same dynamic estimation framework developed above. A straightforward analogy to the basic inflation equation 2 is an equation explaining changes in wage rates $\left(w_{t}\right)$ relative to trend productivity $\left(\theta_{t}^{*}\right)$ by its own lagged values and the same set of demand and supply variables that enter into the price equation. The difference between the growth rates of wage rates and trend productivity is often called the growth rate of trend unit labor cost $\left(w-\theta^{*}\right)$. Thus

$$
\left(w-\theta^{*}\right)_{t}=g(L)\left(w-\theta^{*}\right)_{t-1}+b(L)\left(U_{t}-U_{t}^{N}\right)+c(L) z_{t}+\epsilon_{t} .
$$

As originally suggested by Christopher Sims, the identification of a wage equation that is separate from the price equation is problematic. ${ }^{16}$ One approach might be to include in the wage equation different sets of demand and supply terms as explanatory variables from those included in the price equation. But this is implausible a priori, since any variable relevant as a determinant of price change may also be relevant for participants in the wage-setting process, and vice-versa for prices. Another approach might be to restrict the contemporaneous coefficient of wages on current prices or prices on current wages, but this is arbitrary as well. In this paper I estimate the time-varying NAIRU based on equation 5, which is a direct analogy to equation 2 and includes the same explanatory variables, on the grounds that the variables relevant for wage behavior are similarly relevant for price behavior.

However, equation 5 is restrictive in that it does not allow for feedback from prices to wages. In the present context, it is of particular interest whether wage changes were restrained by the beneficial supply shocks that reduced the rate of price inflation, and whether price changes were restrained by factors that limited wage changes, for example, worker insecurity. An alternative wage equation, leaving open

15. See Franz and Gordon (1993).

16. Sims (1987). 
the relative importance of wage-wage and price-wage feedback, can be written as follows:

$$
\begin{aligned}
\left(w-\theta^{*}\right)_{t}=g(L)\left(w-\theta^{*}\right)_{t-1} & +h(L) p_{t-1} \\
& +b(L)\left(U_{t}-U_{t}^{N}\right)+c(L) z_{t}+e_{t}
\end{aligned}
$$

Equation 6 is the same as equation 5 but with the addition of the lagged price inflation terms. A simple method of estimating the relative importance of lagged wage and price inflation is to transform equation 6 by adding and subtracting $h(L)$ times the lagged trend unit labor cost terms:

$$
\begin{aligned}
\left(w-\theta^{*}\right)_{t}= & {[g(L)+h(L)]\left(w-\theta^{*}\right)_{t-1} } \\
& -h(L)\left(w-\theta^{*}-p\right)_{t-1}+b(L)\left(U_{t}-U_{t}^{N}\right) \\
& +c(L) z_{t}+e_{t} .
\end{aligned}
$$

The sum of $g(L)$ and $h(L)$ coefficients can be constrained to equal unity, which imposes the natural rate hypothesis. The freely estimated sum of coefficients $(\Sigma h)$ indicates the weight on lagged prices in the determination of trend unit labor cost, while $1-\Sigma h$ indicates the weight to be applied to wage-wage feedback. Henceforth I call the $w-\theta^{*}-p$ term the change in trend labor share; note that this differs from the change in labor's share in equation 4 only through the replacement of actual productivity change $(\theta)$ by trend productivity change $\left(\theta^{*}\right)$. By analogy, feedback from wages to prices can be estimated by the "dual" to equation 7 :

$$
\begin{aligned}
p_{t}=[g(L)+h(L)] p_{t-1}+h(L) & \left(w-\theta^{*}-p\right)_{t-1} \\
& +b(L)\left(U_{t}-U_{t}^{N}\right)+c(L) z_{t}+e_{t},
\end{aligned}
$$

where the change in trend labor share appears with a positive sign, in contrast to its negative sign in equation 7 .

To summarize, there are four sets of equations to estimate. While they all contain the unemployment gap and the same set of supply shock terms, they differ in the dependent variable, lagged dependent variable, and lagged trend labor cost term, as follows: 
Dependent variable

Price change

Trend unit labor cost change

Price change

Trend unit labor cost change
Lagged dependent variable

Price change

Trend unit labor cost change

Price change

Trend unit labor cost change
Trend labor share?

No

No

Yes

Yes

\section{Basic Data and the Extent of the Inflation Surprise}

The postwar inflation experience in the United States is well-known. There are three basic price indexes for final goods: the chain-weighted GDP deflator, the chain-weighted deflator for personal consumption expenditures, and the version of the Consumer Price Index (CPI) that incorporates the current treatment of shelter costs back to 1967 , the socalled CPI-U-X1. When four-quarter moving average rates of change are plotted, the differences among these indexes are minor. Each has twin peaks in 1974-75 and 1980-81 and substantial accelerations of inflation in periods of relatively low unemployment, especially 1956-57, 1965-72, and 1987-90. Common valleys are evident as well, most notably in $1960-65 ; 1972-73$, presumably influenced by the Nixon price controls; 1986, when oil prices collapsed; and 1997-98.

Although I do not present such a plot, for reasons of space, the recent behavior of these price indexes and several wage indexes over the two most recent business cycles is summarized in table 1 . The table also shows the behavior of the two main tightness measures examined in this paper: the unemployment rate and the rate of capacity utilization. The unemployment rate is reported for four calendar quarters: 1987:3 and 1994:3 are chosen for being quarters when the unemployment rate first reached 6.0 percent along a cyclical path toward lower values, 1990:2 is the cyclical peak quarter of the previous business expansion, and 1998:2 is the most recent quarter. Between 1994 and 1998 the unemployment rate declined by more than twice as much as between 1987 and 1990. In contrast, the rate of capacity utilization reveals a reduction in cyclical tightness in the more recent period but an increase in tightness in the earlier period.

For the selected price deflators, table 1 displays the four-quarter changes ending in the same four quarters designated above. All three 
Table 1. Basic Data, Selected Quarters ${ }^{a}$

Percent

\begin{tabular}{|c|c|c|c|c|}
\hline Variable & 1987:3 & 1990:2 & 1994:3 & $1998: 2$ \\
\hline \multicolumn{5}{|l|}{ Excess demand $^{\mathrm{b}}$} \\
\hline Civilian unemployment rate & 6.0 & 5.3 & 6.0 & 4.4 \\
\hline Capacity utilization rate & 81.7 & 82.8 & 83.2 & 82.1 \\
\hline \multicolumn{5}{|l|}{ Prices $^{\mathrm{c}}$} \\
\hline GDP deflator & 3.1 & 4.2 & 2.5 & 1.0 \\
\hline PCE deflator & 4.0 & 4.4 & 2.7 & 0.8 \\
\hline CPI-U-X1 & 4.2 & 4.5 & 2.8 & 1.6 \\
\hline \multicolumn{5}{|l|}{ Wages and productivityc } \\
\hline ECI-total compensation ${ }^{d}$ & 3.2 & 5.0 & 3.2 & 3.4 \\
\hline ECI-wages and salaries ${ }^{d}$ & 3.3 & 4.3 & 3.1 & 3.9 \\
\hline Compensation per hour & 3.3 & 5.5 & 1.5 & 4.2 \\
\hline Average hourly earnings & 2.7 & 3.8 & 2.5 & 4.2 \\
\hline Output per hour & -0.3 & 1.0 & 0.4 & 1.9 \\
\hline
\end{tabular}

deflators exhibit a deceleration during 1994-98 that contrasts with an acceleration between 1987 and 1990, although the earlier accelerations for the PCE deflator and the CPI are quite modest. The table also presents four-quarter changes in four wage indexes and a productivity index. The contrast between wage and price behavior is quite marked. All four wage indexes accelerated in 1994-98. Further, the 1994-98 accelerations in compensation per hour and average hourly earnings were actually greater than for the same indexes in 1987-90. Productivity accelerated in both business cycles over the periods shown.

\section{Quantifying the Price Surprise}

Table 1 suggests that the puzzle of low inflation in the mid-1990s applies to price behavior but not necessarily to wage behavior. Price inflation decelerated sharply as unemployment fell during 1994-98, whereas wage inflation accelerated in all four wage indexes shownby much more in compensation per hour and average hourly earnings than in either Employment Cost Index (ECI) measure used. How much of a surprise was the inflation deceleration of the mid-1990s?

One straightforward way to quantify the inflation surprise is to com- 
pute the forecasting error in my standard inflation equation 2 when the NAIRU is maintained at a constant value throughout the 1980 s and 1990s. The exercise can be carried out with the arbitrary NAIRU series that I used in research in the 1980s and early 1990s and published in successive editions of my macroeconomics textbook until 1993, henceforth the "'textbook NAIRU.', This series rose gradually from the 1950s through the late 1970s, to reflect demographic changes, and after 1978 was fixed at 6.0 percent. As recently as 1994, I assessed the accuracy of this series by running postsample dynamic simulations of equation 2 and noted the absence of substantial drift of predicted from actual values. ${ }^{17}$

Throughout this paper, equations are estimated using a uniform sample period, set of supply variables, and set of lag lengths, chosen to conform with my inflation research since $1982 .{ }^{18}$ The wage data refer to the Employment Cost Index, with ("ECI-TC") and without ("ECI-WS") employee fringe benefits. For details, see appendix A.

The results of the inflation surprise computations are presented in table 2, which shows the actual and fitted values of equation 2 estimated with each of the three price indexes shown in table 1 , and the actual and fitted values of equation 5 for both versions of the ECI. In the case of each dependent variable, the textbook NAIRU is used to compute the unemployment gap, and the sample period ends in 1992:4. Fitted values starting in 1993:1 are computed in a dynamic simulation that feeds back the estimated, rather than actual, values of the lagged dependent variable.

The largest simulation errors in table 2 are for the rate of change of the PCE deflator (below, I present the complementary result that the estimated TV-NAIRU for the PCE deflator declines more than for the other price indexes between the late 1980s and 1998). Errors for the two trend unit labor cost variables are much smaller, and indeed, the error is positive for the ECI-WS, indicating that the acceleration in the ECI for wages and

17. Gordon (1994). I found no evidence that the actual inflation rate was drifting down relative to the predicted inflation rate that assumed a fixed NAIRU of 6.0. However, it soon became evident that the fixed NAIRU approach should be abandoned, and my first paper on the TV-NAIRU was presented less than a year later (Gordon, 1995).

18. That is, since Gordon (1982). The one change is that the present paper uses a shorter sample period, beginning in 1962:1. Thus it is no longer necessary to link the Bureau of Economic Analysis's chain-weighted deflators - available only since 1959to the implicit deflators available for the earlier period. 
salaries after 1992:4 has been greater than would have been predicted by equation 5 on the basis of a fixed NAIRU of 6.0 percent. Correspondingly, I show below that the TV-NAIRU estimated for this wage index lies above 6.0 percent during the $1990 \mathrm{~s}$.

A question raised by table 2 is why the inflation rates predicted for 1998:2 using the price deflators were roughly the same as the actual rates for 1994:3 shown in table 1. Why was there no predicted acceleration of inflation, since the natural rate hypothesis forecasts that the actual unemployment rate, continually below the fixed textbook NAIRU of 6.0 percent after 1994:3, should have caused inflation to accelerate? The simple answer is that an acceleration in the predicted values was prevented by the combined effect of the relative import price and relative food-energy variables, which held down the inflation rate by a large amount. While the impact of these variables can be documented with the textbook NAIRU used to construct the results in table 2, I prefer to quantify their impact using newly estimated time-varying NAIRUs (see table 4 below).

\section{New TV-NAIRU Estimates for Inflation, Stripped Inflation, and Labor Cost}

The prediction errors for the price indexes displayed in table 2 suggest that the natural rate hypothesis remains valid in the 1990s only if the estimated TV-NAIRU (incorporating equations 2 and 3) declines substantially from its values in the late 1980s. This is indeed the case. Figure 1 plots the actual unemployment rate against new TV-NAIRUs for the three basic inflation indexes. The TV-NAIRUs are quite stable, remaining within a narrow band between 5.3 and 6.5 percent throughout the past four decades. Since 1989, the TV-NAIRU for the PCE deflator has been somewhat lower than those for the GDP deflator and the CPIU-X1, dropping below 5.5 percent in 1995:1 and stabilizing at 5.31 percent in the last four quarters. The TV-NAIRU for the GDP deflator has fallen from a value of 6.36 percent as recently as 1988:3 to reach a final value of 5.68 percent in 1998:2. 
Table 2. Actual and Simulated Values of Price and Wage Changes, Using Alternative Indexes and Constant NAIRU ${ }^{a}$

Units as indicated

Dynamic simulation

\begin{tabular}{|c|c|c|c|c|c|}
\hline \multirow[b]{3}{*}{ Index } & \multirow{2}{*}{\multicolumn{3}{|c|}{ 1998:2 results ${ }^{\mathrm{b}}$}} & \multicolumn{2}{|c|}{ errors } \\
\hline & & & & \multirow{2}{*}{$\begin{array}{c}\text { Root } \\
\text { mean-squared } \\
\text { error }\end{array}$} & \multirow{2}{*}{$\begin{array}{l}\text { Mean } \\
\text { error }\end{array}$} \\
\hline & Actual & Simulated & Error & & \\
\hline GDP deflator & 1.01 & 2.31 & -1.30 & 0.82 & -0.46 \\
\hline PCE deflator & 0.85 & 2.86 & -2.01 & 1.24 & -1.01 \\
\hline CPI-U-X1 & 1.61 & 3.19 & -1.58 & 0.89 & -0.59 \\
\hline \multicolumn{6}{|l|}{ Trend unit labor cost } \\
\hline ECI-total compensation & 2.35 & 3.13 & -0.78 & 0.99 & -0.52 \\
\hline ECI-wages and salaries & 2.87 & 1.98 & 0.89 & 0.77 & 0.47 \\
\hline
\end{tabular}

Source: Author's calculations

a. Specification of equations given by equations 2 and 5 in text; sample period is 1962:1-1992:4 Dynamic simulation is from 1993:1 to 1998:2. See appendix A for detalls of variables and lag lengths

b Four-quarter percent changes.

\section{The Smoothness Issue}

The smoothness issue becomes evident when equations 2 and 3 are examined. One faces the inescapable choice of either setting the NAIRU as a constant and allowing all the residual variation to remain in the error term of equation 2, or allowing some or all of the residual variation to create movements in the TV-NAIRU. In their latest research, Stock and Watson allow the standard deviation term $\left(\tau_{\eta}\right)$ to be estimated. ${ }^{19}$ Identifying this parameter does not restrict the relationship between the variances of the error terms in equations 2 or 3 ; the model is identified by the assumption that the TV-NAIRU is a random walk (or, more generally, integrated of order one). They prove that if the variance of the change in the TV-NAIRU is small relative to the variance of the error in equation 2 , their estimator is asymptotically median unbiased.

In the present paper, I adopt this new methodology. ${ }^{20}$ My baseline estimates of the TV-NAIRU are based on Stock and Watson's medianunbiased estimator, $\tau_{\eta}$; for the GDP deflator, the estimate is 0.090 .

19. Stock and Watson (1998b).

20. The details of this approach as applied to estimation of the TV-NAIRU are laid out in Stock (1998). 
Figure 1. Actual Unemployment Rate and TV-NAIRUs for Price Indexes, 1961-98

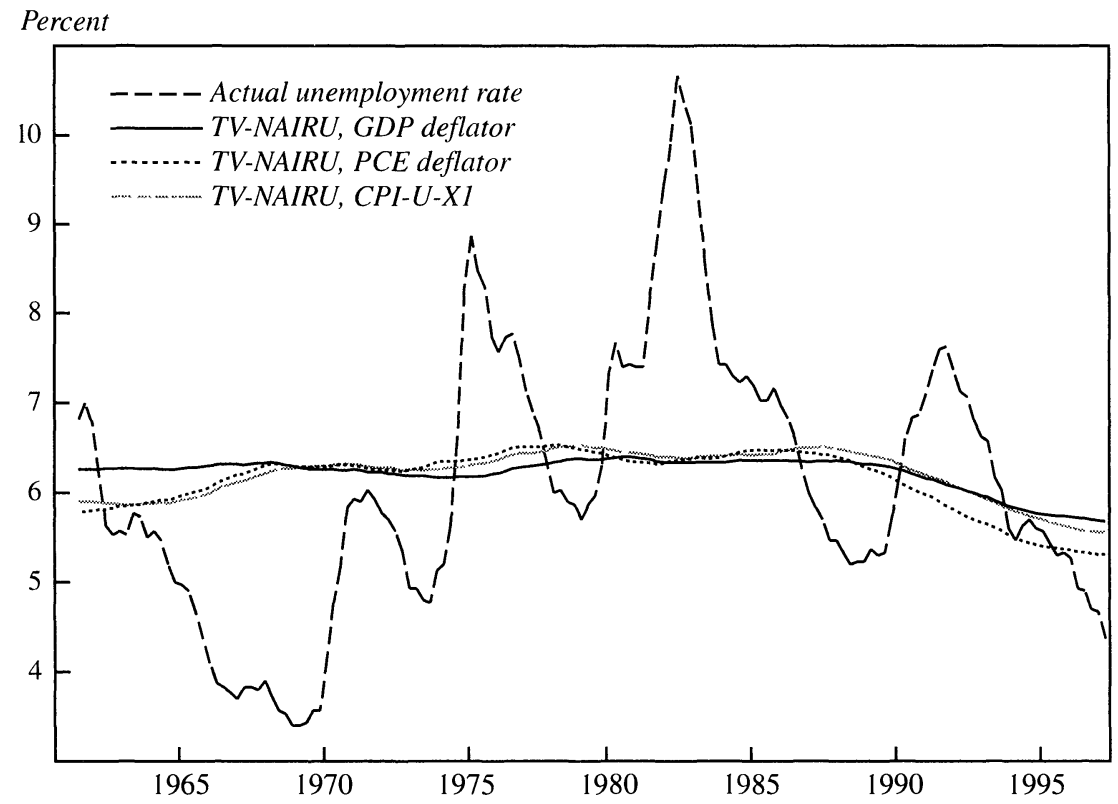

Source Worldwide web page of the Bureau of Labor Statıstıcs and author's calculations

However, this point estimate changes with the specification and it also has considerable sampling uncertainty. Moreover, it is useful to contrast the TV-NAIRUs obtained by this new method with those obtained using the judgmental method set forth in my previous paper, whereby $\tau_{\eta}$ is chosen so that the TV-NAIRU is allowed to vary, subject to the constraint that it is not to exhibit short-term reversals. ${ }^{21}$ As a sensitivity analysis, therefore, I also consider alternative values for this standard deviation.

Figure 2 illustrates the effects of estimating equation 2 for the GDP deflator using four different values for the imposed standard deviation: $0.045,0.090,0.136$, and 0.271 . The solid line plots the TV-NAIRU series that results from imposing a standard deviation of 0.090 , as henceforth in this paper. ${ }^{22}$ With higher standard deviations, the result-

21. See Gordon (1997).

22. The corresponding coefficients are reported below in table 3 . 
Figure 2. TV-NAIRUs for the GDP Deflator, Alternative Standard Deviations, 1961-98

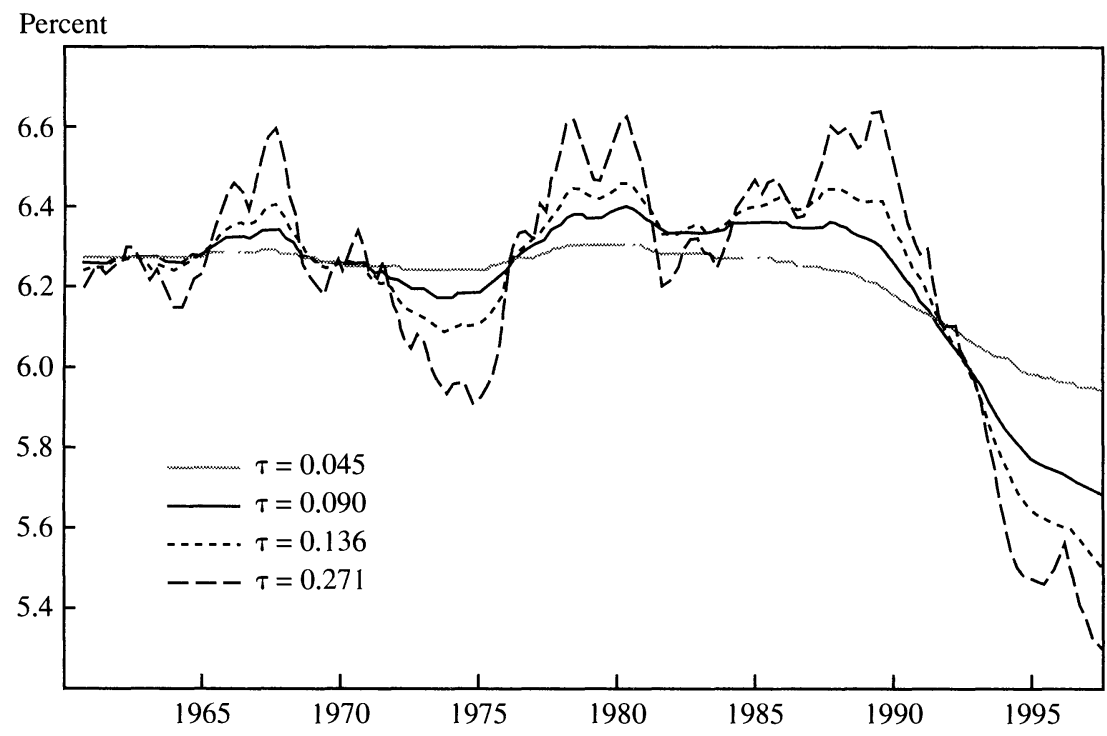

Source Author's calculations

ing series exhibit short-term reversals that are slight for a value of 0.136 and increasingly noticeable for a value of $0.271 .{ }^{23}$ Imposing a lower standard deviation of 0.045 results in a slightly smoother series.

Clearly, the extent to which the TV-NAIRU declines between the late 1980s and 1998 depends on the choice of smoothness parameter. As the smoothness parameter is increased across the four alternative values shown in figure 2 , the series declines by $0.38,0.67,0.84$, and 1.15 percentage points, respectively, between 1988:1 and 1998:2. The criterion that the resulting TV-NAIRU series be free of short-term reversals might lead some to stop at a higher standard deviation, such as 0.136 instead of 0.090 ; and any choice of a higher standard deviation will boost the amount by which the estimated TV-NAIRU declines in

23. The computer programs that implement the methodology of Stock and Watson (1998b) do not directly constrain the value of the $\tau$ parameter, but rather a related parameter, $\lambda$. The research in this paper is based on integer values of $\lambda$ that translate into noninteger decimals for $\tau$. 
the 1990s and reduce the errors reported below in explaining the observed inflation rates of 1998. In the conclusion to this paper, however, I provide a complete decomposition of the inflation surprise of the 1990s, consisting of two error terms, the part of the decline in the TVNAIRU that the model cannot explain, and the remaining residual error. The higher the assumed standard deviation of the TV-NAIRU, the larger will be the part of the decline that the model cannot explain and the smaller will be the remaining residual error.

\section{Estimated Coefficients}

Table 3 displays the estimated coefficients for equations 2 and 5 for the GDP and PCE deflators and the two labor cost variables. The coefficients on the deflator equations are similar to my previous research, with those on the sum of lagged dependent variables very close to unity, those on the sum of unemployment gap variables around -0.6 , those on the productivity deviation around -0.1 , those on the relative import price of 0.1 , those on the food-energy effect of about 0.7 for the consumption deflator but an insignificant 0.2 for the GDP deflator. ${ }^{24}$ The bottom panel of the table displays results of postsample dynamic simulations that truncate the sample period at 1992:4. Both price equations overpredict the rate of inflation in the first half of 1998 by roughly 1 percentage point.

The coefficients for the labor cost equations (using the specification in equation 5) are similar to those in the inflation equations, as are the goodness-of-fit statistics. ${ }^{25}$ The slope of the Phillips curve is somewhat flatter, and neither the food-energy nor productivity variables are significant. However, both the import price effect and the "Nixon controls

24. See Gordon (1982, table 2, pp. 103-04; 1997, table 1, p. 25). In the present paper, lags thirteen to twenty-four are highly significant in the price equations reported in table 3 and contribute 30 percent and 27 percent of the total sum of lagged coefficients on the GDP and PCE deflator equations, respectively. While the sum of coefficients on the food-energy effect in the GDP deflator equation is insignificant, an exclusion test indicates that this set of lagged variables makes a contribution to the fit of the equation at a better than 1 percent significance level.

25. The ECI series for total compensation and for wages and salaries extend back only to 1980 . For this exercise they are extrapolated back to 1948 with a mix-adjusted average hourly earnings series that I developed in earlier research, which is adjusted for fringe benefits when extrapolating the total compensation ECI. See appendix A for further details. 


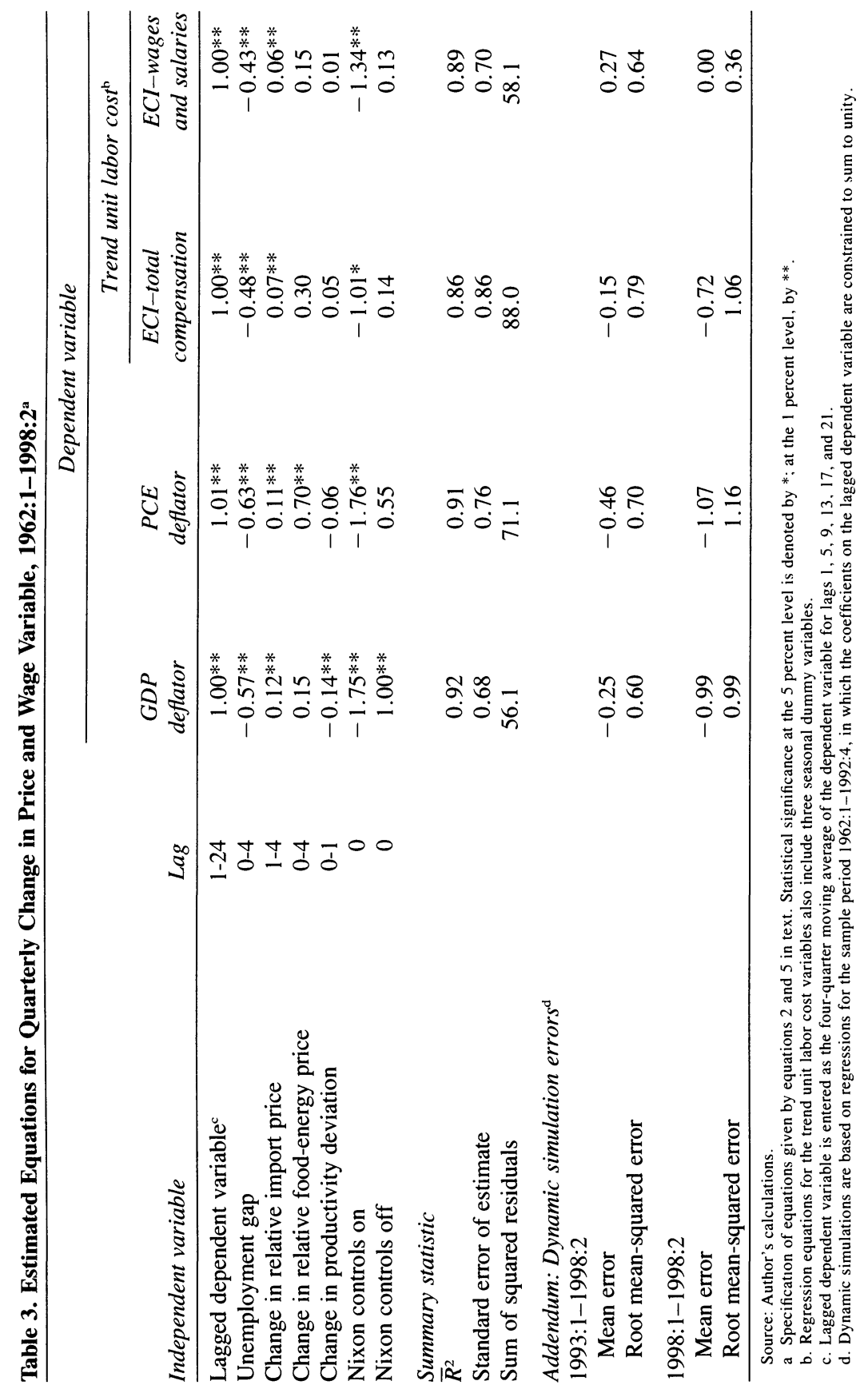


Figure 3. TV-NAIRUs for Wage Indexes and the PCE Deflator, 1961-98

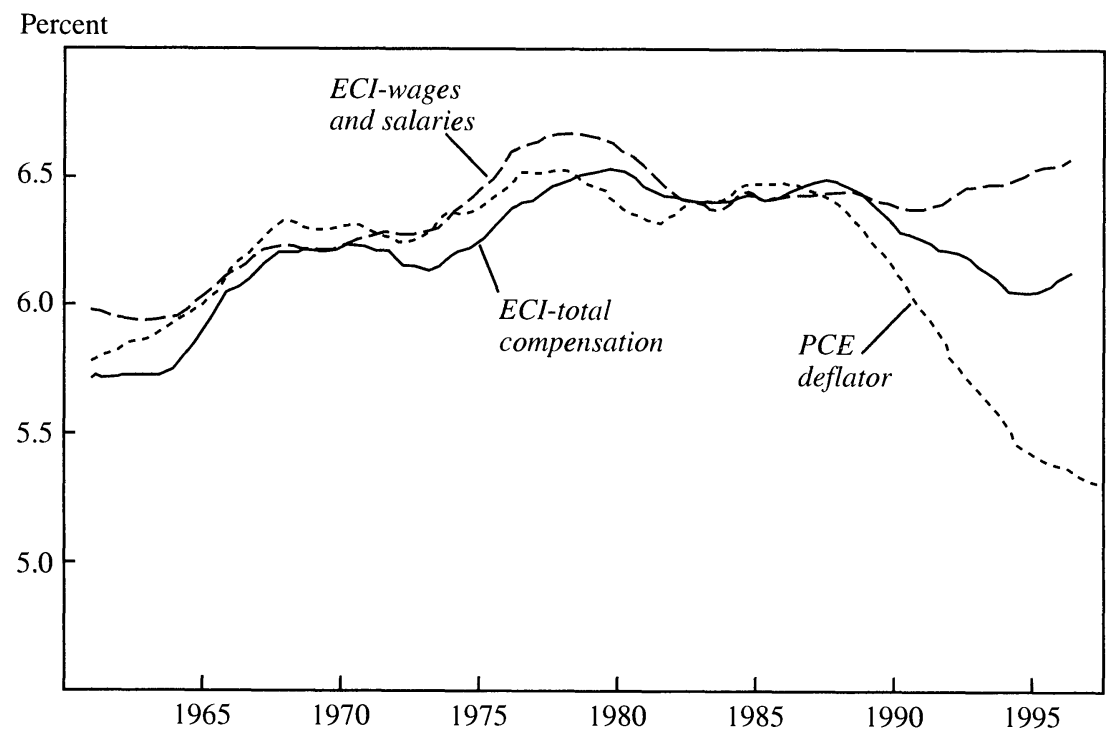

Source: Author's calculations.

on" variable are significant. It is notable that the mean error of the equation for the ECI-WS is exactly zero in early 1998, highlighting the sharp contrast between the wages and salaries version of the ECI and the other variables already evident in the forecasting errors of table 2.

Figure 3 presents the TV-NAIRU estimates for the two trend unit labor cost series in comparison with the basic TV-NAIRU estimate for the PCE deflator. As can be seen, the trend unit labor cost TV-NAIRUs display very similar behavior to the series for the PCE deflator until the 1990s, when they diverge markedly. In contrast to the plummeting TVNAIRU for the PCE deflator, that for ECI-WS creeps up somewhat to 6.55 percent throughout 1996-98, while that for the ECI-TC declines only slightly and reverses itself, to end at 6.13 percent in 1998:2. The fact that the TV-NAIRU for ECI-WS is roughly the same in 1998 as in 1988 indicates that most of the corresponding 0.3 percentage point decline for the ECI-TC can be attributed to the sharp decline in the rate of increase of benefit compensation over the 1990s. 


\section{Contribution of Supply Shock Variables}

As indicated in table 3 , the specification of the basic inflation equation 2 includes four sets of supply shock variables (food and energy prices, import prices, productivity deviation, and Nixon price controls) in addition to lagged inflation and the unemployment gap. In this section I am particularly interested in quantifying the degree to which the significant post-1992 decline in real import prices, reinforced by a decline in real food and energy prices, explains the absence of an accelerating inflation rate in the mid-1990s despite the relatively low unemployment rate. ${ }^{26}$ One way to assess the impact of food-energy and import prices in holding down inflation is to estimate the basic equation for each price index through 1992:4 and compute a dynamic simulation through 1998:2 using the previously estimated TV-NAIRU but artificially setting the food-energy and import price variables equal to zero. The results of this exercise for both the GDP and PCE deflators are summarized in table 4. The third column displays for 1998:2 the simulation errors with actual values of the import and food-energy effects and, by contrast, the errors when either or both effects are set to zero. The results indicate that the food-energy and import price effects in the four quarters ending 1998:2 were holding down inflation in the GDP deflator by 1.42 percentage points and in the PCE deflator by 1.39 percentage points, and that most of this difference was made by the import price effect. These effects combine the static impact of the coefficients as shown in table 3 , which contribute about 0.93 percentage point to the PCE deflator, and the dynamic feedback from the lagged inflation variable, which contributes the remainder. ${ }^{27}$

\section{Explaining the Decline in the NAIRU}

I have shown that the combined impact of import prices and foodenergy prices helps substantially in the explanation of why inflation did

26. The four-quarter rate of change of the relative import price variable was -6.34 percent in 1997:2 and -6.00 percent in 1998:2; the corresponding figures for the foodenergy effect were -0.19 percent and -0.39 percent, respectively.

27. Taking the PCE deflator coefficients in table 3 and the values of the variables reported in the previous footnote, the static import price effect is 0.11 times -6.0 , and the food-energy effect is 0.70 times -0.39 . 
Table 4. Actual and Simulated Values of Price Changes, Using Alternative Indexes and Time-Varying NAIRU ${ }^{\mathrm{a}}$

Units as indicated

Dynamic simulation

\begin{tabular}{cc}
\multicolumn{2}{c}{ error } \\
\hline Root & \\
mean-squared & Mean \\
error & error
\end{tabular}

\begin{tabular}{|c|c|c|c|c|c|}
\hline \multirow[b]{2}{*}{ Index } & & & & \multirow{2}{*}{ error } & \multirow[b]{2}{*}{ error } \\
\hline & Actual & Simulated & Error & & \\
\hline \multicolumn{6}{|l|}{$G D P$ deflator } \\
\hline Actual values & 1.01 & 1.78 & -0.77 & 0.60 & -0.25 \\
\hline Omitting food-energy effect & 1.01 & 1.91 & -0.90 & 0.65 & -0.32 \\
\hline Omitting import price effect & 1.01 & 3.08 & -2.07 & 1.16 & -0.85 \\
\hline Omitting both effects & 1.01 & 3.20 & -2.19 & 1.22 & -0.91 \\
\hline \multicolumn{6}{|l|}{ PCE deflator } \\
\hline Actual values & 0.85 & 1.90 & -1.05 & 0.70 & -0.46 \\
\hline Omitting food-energy effect & 0.85 & 2.29 & -1.44 & 0.96 & -0.66 \\
\hline Omitting import price effect & 0.85 & 2.90 & -2.05 & 1.18 & -0.95 \\
\hline Omitting both effects & 0.85 & 3.29 & -2.44 & 1.43 & -1.14 \\
\hline
\end{tabular}

Source. Author's calculations

a. Specification of equations given by equation 2 in text, sample period is 1962.1-1992 4 Dynamic sımulation is from 1993:1 to $1998 \cdot 2$. See appendix A for details of varıables and lag lengths

b Four-quarter percent changes

not accelerate in 1996-98. This does not, however, explain the decline in the TV-NAIRU for the deflators, since the influence of the supply shock variables is controlled in the process of estimating the TVNAIRU. Stated another way, the combined impact of import prices and food-energy prices does not help to explain why actual inflation decelerated rather than staying roughly stable. I now consider to what extent the decline in the TV-NAIRU depicted in figure 1 can be attributed to the role of computer prices, medical care prices, and improvements in the measurement of prices.

Table 5 provides, for selected quarters, basic data from the Bureau of Economic Analysis (BEA) on the shares of computers and medical care in both GDP and personal consumption expenditure, as well as four-quarter changes in the deflators for GDP, PCE, total computers, consumption computers, and medical care goods and services. In view of the much-hyped new economy, it is surprising to learn that the nominal share of computers (including producers' durable equipment, consumption, government, and net exports) did not grow at all between 1988 and 1998. The share of computers in real GDP grew enormously, 
Table 5. Data on Computers and Medical Care, Selected Quarters

Percent

\begin{tabular}{lrrrr}
\hline Item & & & & $\begin{array}{c}\text { Change } \\
\text { 1988-98 }\end{array}$ \\
\hline Nominal expenditure shares & $1988: 1$ & $1993: 1$ & $1998: 2$ & 1988- \\
Total computers in GDP & & & & \\
Consumption of computers in PCE & 0.2 & 0.9 & 1.2 & 0.0 \\
Medical care goods and services in GDP & 9.6 & 12.1 & 11.9 & 0.2 \\
Medical care goods and services in PCE & 14.4 & 17.6 & 17.4 & 3.0 \\
Four-quarter rates of change of deflators & & & & \\
GDP deflator & 3.0 & 2.7 & 1.0 & -2.0 \\
PCE deflator & 3.7 & 2.9 & 0.9 & -2.8 \\
Total computers & -9.6 & -19.8 & -33.5 & -23.9 \\
Consumption of computers & -7.7 & -29.1 & -34.3 & -26.6 \\
Medical care goods and services & 6.0 & 6.0 & 2.1 & -3.9 \\
\hline
\end{tabular}

Source Unpublished data provided directly by the Bureau of Economic Analysıs

a In lower panel, column gives change in the four-quarter rates of change

from 0.6 to 6.1 percent, but this simply reflects the sharp decline in computer prices rather than an increase in the importance of computer spending. It is the nominal shares that are used in the computation of chain-weighted deflators and that determine the impact of computer prices on overall inflation. The share of medical care is much larger than that of computers in both GDP and PCE, and it grew by a much larger absolute amount between 1988 and 1993, after which it remained on a high plateau.

The growing impact of computers on overall inflation performance reflects not the increase in their nominal share but rather a sharp acceleration in their rate of price decline: from an average annual rate of - 13 percent during 1988-93 to -28 percent during 1993-98, reaching a peak of -37 percent in mid-1997. With a share of 1.2 percent in GDP and a rate of price decline of -34 percent in the year ending 1998:2, computers deducted -0.41 percentage point from the rate of change of the GDP deflator, helping to explain why inflation has recently been so low (the actual impact is more severe than -0.4 , due to the dynamic contribution of the lagged dependent variable). It is important to note that if both the computer share in spending and the rate of price decline stabilize at present levels, computers will make no further contribution to the deceleration of inflation.

The lower panel of table 5 contrasts the inflation rates of the GDP 
and PCE deflators with the implicit deflator of medical care. It shows that medical care inflation substantially boosted overall inflation in both 1988 and 1993, with a wedge that declined to zero in 1996-97 but reemerged in 1998 when overall inflation decelerated further but medical care inflation did not.

In addition to computers and medical care, a third factor holding down the measured rate of inflation has been changes in measurement methodology during the 1990s. Measurement improvements in the CPI are estimated to have reduced measured inflation relative to actual inflation by an amount that grew gradually from -0.1 percentage point in 1992 to -0.46 percentage point in early 1998 . Moreover, the BEA's 1998 benchmark revision has, in translating price changes for individual CPI components into the measures used in the PCE deflator, introduced several changes in CPI methodology that were applied retroactively as far back as 1995:1. The net impact of these measurement changes was to reduce the measured inflation rate in early 1998 by 0.73 point compared with the rate that would have been estimated under the methodology used before $1992 .{ }^{28}$

Table 6 computes the contributions of computers, medical care, and the CPI measurement adjustment to GDP and PCE inflation, as well as to the TV-NAIRU, in the four-quarter periods ending 1988:1, 1993:1, and 1998:2. The fourth column measures the change between 1988:1 and 1998:2. Of particular importance are the data showing the impact of the three factors taken together: from 0.14 percentage point in 1988:4 to -0.60 percentage point in 1998:2 for the GDP deflator (a change of -0.74 percentage point), and from 0.35 to -0.45 percentage point for the PCE deflator (a change of -0.80 percentage point). To summarize, it was determined above that the static impact of the import price and food-energy terms was to hold down the rate of change of the PCE deflator by -0.93 percentage point in the four quarters ending 1998:2, and these three "new" supply shocks contribute another -0.80 percentage point in reducing inflation between 1993 and 1998. Thus the total static impact of the five supply shocks is -1.73 percentage points

To determine how much difference the three new factors make to the TV-NAIRU, one can strip computers, medical care, and the CPI measurement adjustment, as well as all three effects together, from the

28. See appendix A for details and sources for the CPI measurement adjustment. 
Table 6. Effects of Computers, Medical Care, and Price Measurement on Inflation and the TV-NAIRU, Selected Quarters

Percent

\begin{tabular}{lrrrc}
\hline & & & & Change \\
Item & $1988: 1$ & $1993: 1$ & $1998: 2$ & $1988-98^{\mathrm{a}}$ \\
\hline GDP deflator, impact of stripping & & & & \\
$\quad$ Computers & -0.15 & 0.22 & -0.40 & -0.25 \\
$\quad$ Medical care goods and services & 0.30 & 0.44 & 0.16 & -0.14 \\
$\quad$ Changes in price measurement & 0.00 & -0.07 & -0.36 & -0.36 \\
$\quad$ All three components & 0.14 & 0.13 & -0.60 & -0.74 \\
PCE deflator, impact of stripping & & & & \\
$\quad$ Computers & -0.03 & -0.09 & -0.16 & -0.13 \\
$\quad$ Medical care goods and services & 0.37 & 0.65 & 0.23 & -0.14 \\
$\quad$ Changes in price measurement methods & 0.00 & -0.10 & -0.52 & -0.52 \\
All three components & 0.35 & 0.44 & -0.45 & -0.80 \\
TV-NAIRU for GDP deflator & & & & \\
Official & 6.36 & 6.05 & 5.68 & -0.67 \\
Deflator stripped of & & & & \\
$\quad$ Computers & 6.34 & 6.09 & 5.76 & -0.58 \\
$\quad$ Medical care & 6.24 & 6.05 & 5.69 & -0.55 \\
$\quad$ Measurement adjustments & 6.36 & 6.16 & 5.86 & -0.50 \\
$\quad$ All three components & 6.27 & 6.22 & 6.03 & -0.24 \\
TV-NAIRU for PCE deflator & & & & \\
Official & 6.42 & 5.77 & 5.31 & -1.11 \\
Deflator stripped of & & & & \\
$\quad$ Computers & 6.44 & 5.81 & 5.37 & -1.07 \\
$\quad$ Medical care & 6.28 & 5.78 & 5.40 & -0.88 \\
$\quad$ Measurement adjustments & 6.46 & 5.96 & 5.59 & -0.87 \\
$\quad$ All three components & 6.29 & 5.96 & 5.67 & -0.62 \\
\hline
\end{tabular}

Source: Author's calculations based on unpublıshed data provided directly by the Bureau of Economıc Analysıs a Third column minus first column.

deflators, and then compute new TV-NAIRUs for each stripped deflator. By comparing each stripped TV-NAIRU to the nonstripped series plotted in figure 1 , one can assess the total impact of the three new factors on the TV-NAIRU. Table 6 compares each stripped TV-NAIRU with the nonstripped TV-NAIRU and in the fourth column calculates the change between 1988:1 and 1998:2. For the GDP deflator, the stripping process explains -0.43 percentage point of the total decline in the TVNAIRU of -0.67 percentage point. For the PCE deflator, the stripping process explains -0.49 percentage point of the total TV-NAIRU decline of -1.11 percentage points. Thus the stripping exercise explains 
64 percent of the decline in the TV-NAIRU for the GDP deflator and 44 percent for the PCE deflator.

\section{Contrasts between Wages and Prices and between Unemployment and Capacity Utilization}

The basic data in table 1 and the TV-NAIRUs shown in figures 1 to 3 call attention to a sharp contrast between the behavior of wages and that of prices in the mid-1990s. Far from exhibiting weak behavior as a result of structural factors in labor markets, such as labor insecurity or weak unions, wage changes have if anything accelerated more than would have been expected from the precedent set in the economic expansion of the late 1980s. The TV-NAIRU for the wage and salary component of the ECI drifts up slightly from 1990 to 1998, contrary to the decline in the series for the price deflators; and although the TVNAIRU for the total compensation ECI measure does decline slightly, this can be entirely attributed to a slowdown in benefit growth, which is largely the counterpart of the moderation in medical care inflation.

The contrasting behavior of prices and wages raises the intriguing issue of how they have interacted. Was there feedback from prices to wages, so that the influence of the five beneficial supply shocks identified above held down wages? Was there feedback from wages to prices such that without the influence of accelerating wages, inflation would have decelerated even more than actually occurred? I test for the presence of feedback effects by estimating equations 7 and 8 , which introduce the change in trend labor share (that is, the difference between the changes in trend unit labor cost and in the appropriate inflation rate) into the wage and price equations, respectively. Positive feedback from wages to prices, as in equation 8 , should yield a positive sum of coefficients on the change in trend labor's share, whereas positive feedback from prices to wages, as in equation 7 , should yield a negative sum of coefficients.

The results of estimating equations 7 and 8 are presented in table 7 , which shows the impact of adding eight lags of changes in the trend labor share variable to each of the equations displayed in the first three columns of table 3 . The table reports changes in the regressions' summary statistics, the standard error of estimate and the sum of squared 


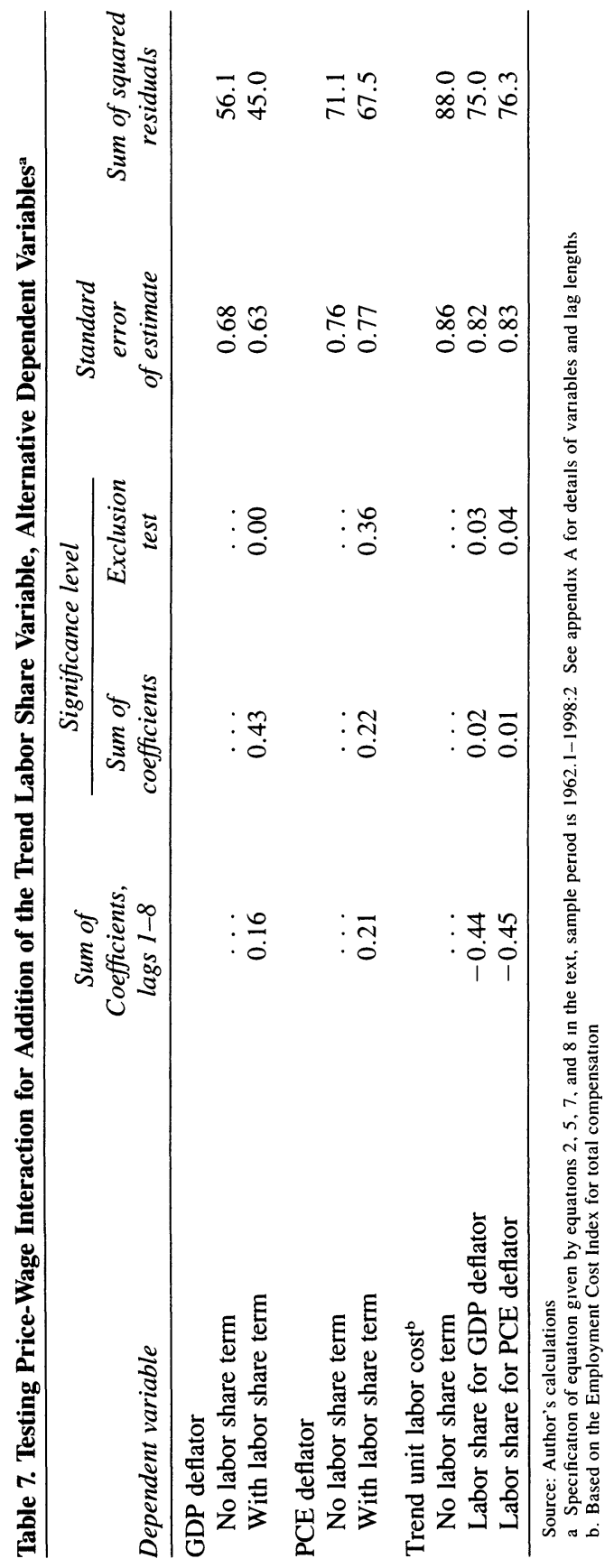


residuals, that result from adding the set of trend labor share lags; it also reports the sums of coefficients, the significance level of the sum, and the significance level of an exclusion test on the set of eight lagged variables. The results indicate that in the wage equations (the last two rows) the sum of coefficients on the feedback terms is highly significant and has the correct sign, whereas in the price equations (the second and fourth rows) the sum of coefficients is not significant. These results suggest that the deceleration of inflation in 1994-98 helped to keep wages from accelerating more than they actually did, but there is no parallel claim that the acceleration of wages helped to keep prices from decelerating more than they actually did.

I have also estimated a full set of TV-NAIRUs (not shown) for each equation summarized in table 7. With wage feedback, in 1998:2 the price equations exhibit TV-NAIRUs that are roughly 0.15 percentage point lower than those displayed in figure 1, indicating that allowing for the acceleration of wages, the puzzle of low inflation would have been even deeper than suggested by the basic equation 2 that ignores wage-to-price feedback. With price feedback from the consumption deflator, the TV-NAIRU for the ECI-TC wage variable is almost identical to the basic result for equation 5 shown in figure 3 . With price feedback from the GDP deflator, in 1998:2 the TV-NAIRU is 6.31 percent compared with 6.08 percent with that feedback effect indicating that allowing for the feedback from decelerating prices boosts the extent to which wages exhibit an acceleration.

\section{The Capacity Utilization Rate as an Alternative Demand Variable}

The basic data presented in table 1 also display a contrast between the behavior of the unemployment rate and that of the capacity utilization rate (for manufacturing, mining, and utilities) over the past two business expansions. From 1987 to 1990 the capacity utilization rate increased, while from 1994 to 1998 it decreased. It is possible to estimate a NAIRCU (or "nonaccelerating inflation" rate of capacity utilization); the analogy to the sharp decline in the TV-NAIRU in the 1990s for the price deflators would be a sharp increase in the corresponding TV-NAIRCU. However, as illustrated in figure 4, only a mild increase is observed. Since the variance of the capacity utilization rate is about three times that of the unemployment rate, the decline of about 
Figure 4. Actual Capacity Utilization Rate and TV-NAIRCU for the PCE Deflator, 1961-98

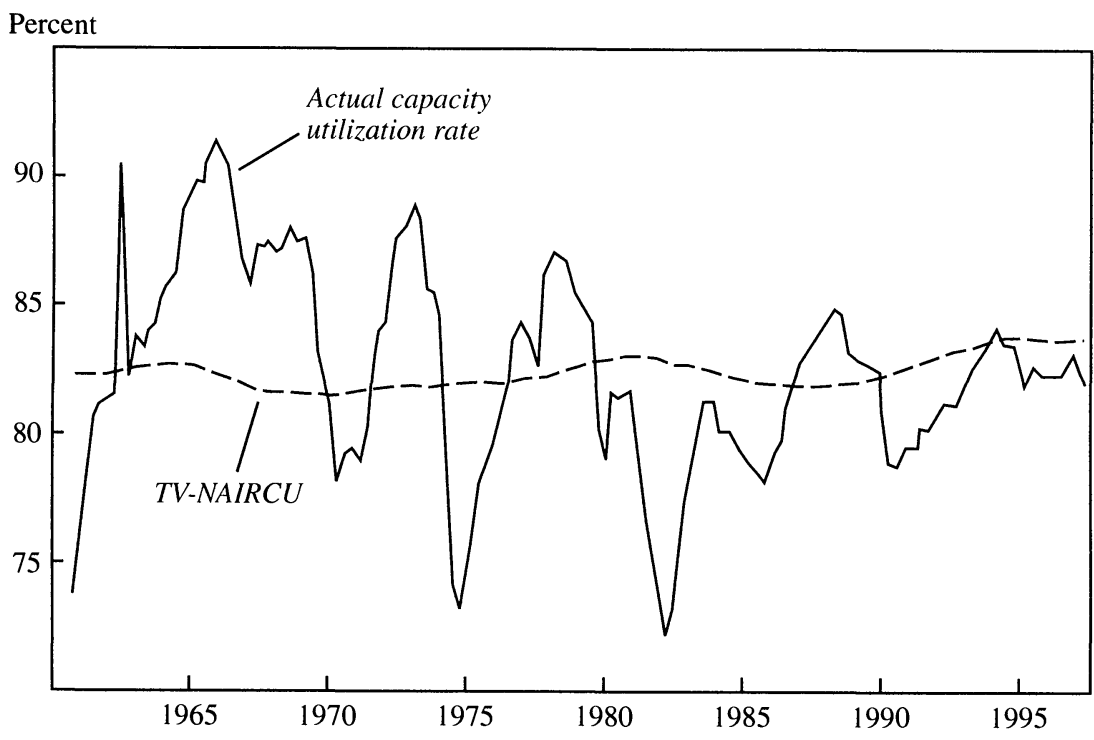

Source: Worldwide web page of the Bureau of Economic Analysis and author's calculations.

1 percentage point in the TV-NAIRU for the unemployment rate observed for the PCE deflator in figure 1 and table 6 should have been accompanied by an increase in the TV-NAIRCU of about 3 percentage points. In fact, the TV-NAIRCU increased by about 1 percentage point between 1990 and 1998. Figure 4 shows that actual capacity utilization was below the TV-NAIRCU in 1998, consistent with decelerating inflation, whereas in figure 1 the actual unemployment rate was below the TV-NAIRU, implying accelerating inflation. ${ }^{29}$

29. Using the methodology of this paper, I have examined an additional measure of demand tightness: the demographically adjusted unemployment rate recently developed by Robert Shimer (forthcoming). My results confirm Shimer's view that changes in the TV-NAIRU can be almost entirely attributed to changes in the age composition of the unemployed-but only through 1990. Contrary to his claim that the same is true of the 1990s, I find that the TV-NAIRU based on Shimer's data on the demographically adjusted unemployment rate actually declines slightly more than the standard TVNAIRU series for the PCE deflator between 1992 and 1998. 


\section{Conclusion}

This paper attempts to explain the outstanding macroeconomic performance of the U.S. economy in the 1990s. The explanation of the socalled Goldilocks economy turns largely, if not entirely, on the explanation of the deceleration of inflation that has accompanied a marked decline in the unemployment rate over 1994-98. The conventional natural rate hypothesis, by contrast, would have predicted that such a decline in the actual unemployment rate would have been accompanied by an acceleration of inflation if the NAIRU had remained constant.

\section{Decomposition of Proposed Explanations}

How great would that predicted acceleration have been, and how can the alternate observed deceleration be explained? A complete decomposition of the contribution of this paper is provided in table 8 . I take as a point of departure the textbook NAIRU of an arbitrary and fixed 6.0 percent that I used in research prior to 1995 , which predicts that the inflation rate for the GDP deflator would have accelerated from 2.5 percent in 1994:3 to 3.73 percent in 1998:2 if there had been no change in the real prices of food, energy, and imports (all figures in this section refer to four-quarter rates of change ending in the designated quarter).

The last row of table 8 reminds one that the inflation rate in 1998:2 was not 3.73 percent but 1.01 percent. This leaves a glaring error of 2.72 percentage points to be explained. Slightly more than half of the required explanation is provided by the contribution of the traditional supply shocks, since the actual declines in the real prices of food, energy, and imports explained a decline in the inflation rate of 1.42 percent. Thus the predicted inflation rate net of the traditional supply shocks that actually occurred was just 2.31 points. Using the estimated TV-NAIRU rather than the fixed NAIRU of 6.0 percent assumed initially further reduces the predicted inflation rate from 2.31 percent to 1.78 percent; of this additional reduction, about half is explained by the role of computers, medical care, and measurement changes. This leaves an unexplained error of -0.77 percentage point in explaining the actual inflation rate of 1.01 percent.

Thus it appears that what this paper leaves unexplained are the unexplained contribution of the decline in the TV-NAIRU and the pure 
Table 8. Decomposition of the Inflation Surprise in the GDP Deflator, 1998:2a

Percent per year

Component of inflation

Change

1. Predicted inflation, constant NAIRU, constant real prices of food, energy, and imports (rows $3-2 \mathrm{c}$ )

2. Contribution of traditional supply shocks
a. Food and energy prices
$-0.13$
b. Import prices
$-1.30$
c. Total
$-1.42$

3. Predicted inflation with actual behavior of supply shocks and constant 2.31 NAIRU

4. Contribution of new supply shocks
a. Computers
b. Medical care
c. Measurement methodology
d. Interaction effect
e. Total, working through decline in TV-NAIRU

$-0.02$

$-0.10$

$-0.08$

$-0.26$

5. Predicted inflation with actual behavior of supply shocks and explained portion of decline in TV-NAIRU (rows $3+4 \mathrm{e}$ )

6. Contribution of unexplained decline in TV-NAIRU

7. Predicted inflation with actual behavior of supply shocks and estimated TV- $\quad 1.78$ NAIRU

8. Error term in simulation of inflation (rows $9-7$ )

9. Actual inflation, four quarter change to $1998: 2$

Source: Author's calculations By row, 2 is from table 4, "error for effect" minus "error for actual value" ; 3 is from the first row of table 2, 4 and 6 are from table 6, change 1993.1-1998.2 in TV-NAIRUs for the GDP deflator, prorated among explained and unexplained components; and 7 and 9 are from the first row of table 4

a. Percent changes are four-quarter moving averages

unexplained residual. These add up to 1.04 percentage points, or 38 percent of the original 2.72 point "surprise" on comparing the prediction of the top row of the table with the actual result on the bottom row. Clearly, the decomposition of the unexplained 1.04 percentage points depends on the smoothness parameter $\left(\tau_{\eta}\right)$ imposed on the estimation of the model consisting of equations 2 and 3 . The larger is the assumed standard deviation, the more of the unexplained component of inflation will be attributed to the unexplained component of the decline in the TV-NAIRU and the less to the pure residual.

However, this decomposition of what remains unexplained is sensitive to the use of the TV-NAIRU methodology. Another approach would be to take the predicted value of inflation net of traditional supply shocks (from table 8) and add to actual inflation the full change between 1993 and 1998 contributed by computers, medical care, and measurement methodology, which is 0.80 percentage point in table 6 . This 
would make actual inflation 1.81 percent rather than 1.01 percent, and would reduce the unexplained component from 1.04 percentage points to 0.50 percentage point $(2.31$ from table 8 minus the alternative actual of 1.81$)$. This approach would suggest that only 18 percent $(0.50 / 2.72)$ of the initial inflation surprise remains unexplained.

In other words, the contribution of the three new supply shockscomputers, medical care, and measurement methodology-depends on whether it is fed through the TV-NAIRU and thus is subject to the associated smoothness assumptions, or it is added to the actual inflation rate to create an alternative stripped inflation rate. The new supply shocks make a much bigger difference when this second approach is followed, and this approach is also more symmetrical to the direct treatment of the traditional supply shocks.

This paper goes beyond the attempt to explain the inflation surprise of the 1990s to extend previous work on the TV-NAIRU, which so far has been limited to a model in which price inflation evolves independent of wage changes. Estimates of a model of wage-wage feedback parallel to the standard model of price-price feedback reveals a stark contrast: the estimated TV-NAIRU for total compensation barely declines in the 1990s, and all of the small decline can be attributed to the sharp decline in the rate of change of employee benefits, largely reflecting the transition to HMO-type payment systems for medical care.

I then extend the standard autoregressive price and wage inflation models to allow for wage-to-price and price-to-wage feedback. The sum of the lagged feedback terms is significant only from prices to wages, not from wages to prices. Allowing for such feedback effects alters the estimated TV-NAIRUs only slightly. The results suggest that wages would have accelerated even more during the current economic expansion without the moderating effect of price feedback. Ignoring the insignificant sums of coefficients on the feedback terms in the price equations, prices would have decelerated slightly more without the inflationary impact of wage feedback. Thus when allowance is made for wage-price feedback, the contrast between price and wage behavior deepens.

\section{The Future}

To the extent that this paper attributes most of the inflation surprise of the 1990s to five supply shocks, the two traditional shocks (food- 
energy and import prices) and the three new shocks (computers, medical care, and measurement methodology), it opens debate regarding the likely evolution of these shocks. The continued arrival of new shocks would be required to continue the deceleration of inflation, given a constant unemployment rate. For instance, at a given share of nominal expenditure for computers, the rate of deflation of computer prices would have to continue to accelerate as it did between 1993 and 1998. Steady deflation of computer prices at 40 percent a year, along with a fixed share of computers, would maintain current inflation without any pressure for renewed deceleration or a reversal toward acceleration.

Viewed in this perspective, between 1993 and 1998 the economy benefited from a powerful and interactive push toward decelerating inflation, resulting from appreciation in the dollar, a decline in real oil prices, an accelerated rate of decline of computer prices, a reduced relative rate of inflation in medical care, and a series of measurement improvements in the official price indexes. It is not an unreasonable conjecture that each of these beneficial shocks was temporary, which would imply that inflation in the future will be much more dependent on the gap between the actual unemployment rate and the NAIRU than has heretofore been the case.

The movement of the dollar cannot be forecast; the exchange rate might stabilize and could either depreciate or appreciate. Oil prices may have fallen as far as they can and could exhibit a partial recovery in the next few years. Computer prices may continue to decline at 40 percent per year, but not at 60 percent per year. The medical care revolution may have reached its limit in cost reductions, and henceforth medical care inflation may once again outpace general inflation-a development that already seems in prospect for $1999 .{ }^{30}$ And the improvements in price measurement may be complete; note, especially, that the national accounts have since 1995 incorporated improvements in CPI methodology that will be implemented only in 1999. Thus the net balance of the supply shocks may be shifting from sharp downward pressure on the inflation rate to neutral or even slight upward pressure.

30. See Milt Freudenheim, "Employees Facing Steep Increases in Health Costs,", New York Times, November 27, 1998, p. A1. 


\section{Alternative Explanations}

While this paper explains most of the inflation surprise of the 1990s, it leaves some of it unexplained, and so leaves room for other explanations. The advocates of the new economy view could argue that hightechnology innovation has held down inflation. But they must be careful in explaining how the benefits of high-technology products could have held down measured inflation without boosting measured productivity. A complaint that official price indexes miss some of the impact of such innovation (however justified) cannot be part of the explanation of a mysterious deceleration in measured inflation.

Achieving a full explanation of the decline in the TV-NAIRU for measured price inflation may depend on developing better empirical counterparts of the new economy argument. For instance, high technology involves more than the direct production of computers, as included in the national accounts. The pervasive role of electronic components in many other products, ranging from automobiles to supermarket check-out scanners, may have contributed to lower inflation but is not captured by an analysis that limits the computer effect to the narrow 1.2 percent of GDP included in the official definition.

This paper points toward two main areas for future research. The first is to explain the contrast between decelerating prices and accelerating wages. The easy answer that unmeasured productivity growth has accelerated is unconvincing, because the price deceleration has occurred in measured inflation, and this paper has taken fully into account improvements in measurement methods in the CPI and in the deflators. More plausible answers are likely to focus on developments in product markets that do not apply to labor markets, going beyond the aspects of the computer and medical care industries that are explicitly treated here.

A second, parallel contrast deepens the puzzle. Unemployment has fallen much more than the rate of capacity utilization has risen, once one allows for the much higher cyclical volatility of utilization. Since the utilization measure applies only to manufacturing, mining, and utilities, and not to the vast service sector, this contrast may point to developments in the labor market in the service sector that have generated an increased demand for labor without creating additional pressure on industrial capacity. It is tempting to speculate that the resolution 
of the unemployment-utilization discrepancy lies in the much discussed ability of the American economy (in contrast to the rich European nations) to provide abundant jobs in the service sector-flipping hamburgers, bagging groceries, valet parking, waiting tables-without placing pressure on capacity in the manufacturing sector.

\section{APPENDIX A}

\section{Data}

THE FOLLOWING are the common elements of the estimated equations for price and wage change. The sample period is 1962:1 to 1998:2, or 146 quarters. All right-hand-side variables are allowed to enter with lags. ${ }^{31}$ Supply shock variables include the change in the relative price of imports and the change in the relative price of food and energy. ${ }^{32}$ Dummy variables are included for when the Nixon price controls of 1971-75 went "on" and "off." These dummy variables, and all the other variables, are defined exactly as in all my papers starting with Gordon (1982). An additional explanatory variable is the difference between productivity growth and its trend, reflecting the fact that while

31. Lag lengths are chosen to be identical to those in Gordon (1990). The only smoothing condition imposed on the lag distributions involves the lagged dependent variable, where twenty-four lagged terms enter. Rather than estimating that number of unconstrained coefficients, the lagged dependent variable is entered as a series of fourquarter moving averages of rates of change; for example, the first variable is a fourquarter average of lags $t-1$ to $t-4$, the next $t-5$ through $t-8$, and so forth. The coefficients on the individual moving averages are unconstrained. Exclusion tests indicate that the moving averages representing lags thirteen through twenty-four enter with a significance level of better than 1 percent for each of the three price indexes shown in figure 1 and are thus highly significant. The coefficients on lags thirteen through twentyfour represent 30 percent of the total lagged effect in the equation for the GDP deflator, 24 percent of the total effect for the PCE deflator, and 35 percent of the total effect for CPI-U-X1.

32. The food-energy effect is defined as the difference of the rate of change of the chain-weighted consumption deflator minus the rate of change of the chain-weighted consumption deflator net of food and energy. Also, the change in the real effective exchange rate, included in previous papers, is found to be insignificant in all versions estimated for this paper, presumably because its effect is swamped by that of the relative import price. I therefore exclude it in the results presented here. 
the larger part of any cyclical increase or decrease in productivity is reflected in a movement in profits in the same direction, a small fraction remains to influence the inflation rate in the opposite direction. ${ }^{33}$

Five indexes of price and wage change are studied. These are the official chain-weighted GDP deflator, the chain-weighted PCE deflator, CPI-U-X1, trend unit labor cost for the Employment Cost Index-Total Compensation (ECI-TC), and trend unit labor cost for the Employment Cost Index-Wages and Salaries (ECI-WS). ECI-WS differs from ECITC by excluding employee benefits. Neither ECI variable is available prior to 1980:1. The ECI series are extrapolated backward using two series developed in previous research. For the ECI-WS, I use an index of average hourly earnings in the nonfarm private economy, adjusted for changes in interindustry employment mix and in the importance of overtime pay. ${ }^{34}$ For the ECI-TC, I use the same index multiplied by the ratio of employee compensation to wages and salaries (both from the National Income and Product Accounts) to adjust it for the effective fraction of employer-paid and employee-paid fringe benefits. Because changes in fringe benefits have almost always occurred in the first quarter of the year, each equation for trend unit labor cost includes seasonal dummy variables.

The seasonal dummies must have mean zero in order not to change the mean of the TV-NAIRU. Hence, taking the first quarter of each year as an example, I use dummies equal to $0.75,-0.25,-0.25$, -0.25 rather than the usual $1,0,0,0$. As a result, the compensation version of the wage equations has a higher error variance than the wagesalary version. These appear only in the wage equations (for trend unit labor cost), not in the price equations.

Alternative measures of the TV-NAIRU are estimated for both the GDP and the PCE deflators stripped of three different elements. The first element is computer expenditures for total GDP (including PCE, PDE, government, and net exports) and for PCE. The second is total medical care expenditures, which is entirely a component of PCE and

33. The productivity deviation is defined as the growth rate of the log ratio of actual nonfarm private business output per hour to a log-linear piecewise trend running through $1950: 2,1954: 4,1963: 3,1972: 2,1978: 3,1987: 3$, and 1996:4. The 1987-96 growth rate of this trend is 1.06 percent per year.

34. See Gordon (1971, pp. 115-18) for a full explanation of the construction of this series and a contrast with the conventional data on compensation per hour. 
consists of both services and goods expenditures. The third is the CPI measurement adjustment.

Time-series expenditures on nominal and real expenditures on GDP and PCE computer expenditures and on PCE total medical care expenditures through 1998:2 were provided by Christian Ehemann of the Bureau of Economic Analysis.

The time series on the price measurement adjustment is taken from the Economic Report of the President, February 1998, table 2-4, p. 80, with three qualifications. First, I do not include the 1998 component for " updated market basket," since the PCE and GDP deflators are not affected by the updating of "upper-level" weights in the CPI. Second, I add an additional measurement adjustment beginning in 1992:1, based on graph 1 of U.S. Bureau of Labor Statistics (1997), which compares the "test" (that is, constant measurement methods) CPI with the official Laspeyres CPI. This graph appears to show an average difference between the two indexes of about -0.15 percent per year during 1992 94; I reduce this to -0.10 , to be conservative. Third, I adjust for the fact that the BEA " 'backcast"' the 1999 implementation of " lower level geometric weights"' and several other minor changes to 1995:1. In order to reflect this shift in the measurement methods of the PCE deflator, I take the stated revisions to the PCE deflator in Seskin (1998, table 4, p. 24) and add the absolute value of these revisions to the CPI measurement series. To summarize, the price measurement adjustment used in this paper is as follows: for 1992:1-1994:4, -0.1 percent; for 1995:1-1995:4, -0.53 percent; for 1996:1-1996:4, -0.73 percent; for 1997:1-1997:4, -0.49 percent; and for 1998:1-1998:4, -0.73 percent. The measurement methodology series for the GDP deflator is equal to that for the PCE deflator times 0.7 , roughly the share of personal consumption expenditures in GDP. 


\section{Comment and Discussion}

James H. Stock: From 1993 through mid-1998, the U.S. economy experienced several years of low unemployment and low and falling inflation that is nothing short of extraordinary. What should one make of this experience? Is it transitory, simply good luck, or has the economy changed in a fundamental way? Is the death of the Phillips curve, so long proclaimed, finally a reality?

Although it is widely known that the NAIRU is measured with considerable imprecision, the recent experience is surprising. For example, Staiger, Watson, and I have estimated that in 1989 the NAIRU, based on the GDP deflator, was 6.3 percent, with a 95 percent confidence interval of 5.0 to 7.4 percent. ${ }^{1}$ The United States has now been at or below the lower end of this confidence interval for some time, yet inflation remains quiescent.

In his previous work, Robert Gordon has argued that the unemployment-based Phillips curve has been a trusty and stable relation, at least through the early 1990s. In the current paper, he turns his attention to the events of the past five years. His approach to this puzzle is, sensibly, to ask what went wrong with the constant NAIRU, circa-1992 Phillips curve. He considers four sets of factors that could have contributed to the good inflation performance, given recent unemployment: first, traditional supply shocks, in particular food and energy prices and import prices, which have been included in Gordon's empirical work at least since 1982; second, some new supply shocks, in particular medical prices and computer prices; third, recent measurement improvements

1. Staiger, Stock, and Watson (1997, table 1). 
in the CPI; and fourth, an otherwise unexplained drop in the NAIRU. His empirical strategy is to decompose the error that he would have made had he been asked, at the end of 1992, to forecast the average inflation rate for the four quarters ending in 1998:2, given future values of the unemployment rate, food and energy prices, and his other control variables, but not the future shocks to the Phillips curve.

Gordon concludes that much of the fall in inflation-approximately 1.4 percentage points - is attributable to favorable traditional supply shocks (declining real food and energy prices and import prices), but that declines in the NAIRU have also been an important factor, explaining approximately 0.5 percentage point of the surprisingly good inflation performance. Although the new, lower NAIRU might persist, in all likelihood the favorable supply shocks will not. Thus Gordon's explanation of the Goldilocks economy echoes Goldilocks's fate. On the one hand, the bears do come home, rudely interrupting her sleep and ending her consumption windfall: there is, it turns out, no free lunch. On the other hand, she escapes with no more than a fright, presumably to pursue future policies that depend less heavily on favorable supply shocks.

My comment has three parts. First, I raise some disagreements with aspects of Gordon's conceptual framework, especially the introduction of his new supply shocks. Second, I reestimate his decomposition, altering aspects of his analysis with which I disagree. Third, I return to the claims of proponents of the new economy in light of this evidence and provide some further evidence that the puzzle is not about inflation, but about labor markets. Because of space constraints, this discussion exclusively considers inflation as measured by the GDP deflator.

Part of Gordon's explanation for the recent good news on inflation involves his three new supply shocks: declining real computer prices, moderation in health care inflation, and improvements in methods for measuring inflation. The third of these so-called supply shocks is not a supply shock at all, and it is confusing for Gordon to call it so. If one were modeling river flooding and the units of measurement of river depths had switched from feet to meters, one would not call the resulting break in the series a climate shock; rather, one would just adjust the series so that the units were comparable over time. Similarly, because methods for measuring inflation have changed, one needs to make an adjustment so that historical and current values of inflation are in the 
same "units.", Gordon deserves credit for being the first in this literature to incorporate such an adjustment, but this adjustment has little to do with supply shocks. ${ }^{3}$

Although it is common sense to adjust for known improvements in measurement, the argument for singling out falling computer prices and moderating health care inflation is less clear. Returning to the flooding example, this is a bit like saying that St. Louis suffered flooding because the Mississippi was especially deep although the Missouri was notwhich is no explanation at all. Nor does it explain low inflation to observe that two domestic sectors had falling or stable prices. Over any period, there always will be some sectors that contribute positively to inflation and others that contribute negatively. To justify subtracting the contributions of two such sectors requires arguing that these contributions are qualitatively different from those of the other sectors, in other years, that have been left in. One systematic approach to eliminating outlier sectors is to use a trimmed-mean CPI, or perhaps the median CPI. This issue is more than semantic. Gordon "explains" the decline in the NAIRU in terms of these two price shocks; but if real health care costs start to rise again, would one expect the NAIRU to rise as well? Probably not, because (as I argue below) the decline in the NAIRU seems to be linked to recent developments in labor markets. ${ }^{4}$

As a basis for further analysis, I have recomputed Gordon's decomposition in his table 8 , using a specification that makes these and other minor changes. The motivation for one regressor-the change in pro-

2. This feet to meters view also leads to a different method from Gordon's for performing the dynamic simulations. Rather than treating measurement changes as a shock with dynamic consequences, the dynamic simulation should be performed in basequarter (1992:4) units, and then the forecasts should be converted to current-quarter units.

3. The river depth analogy is imperfect, because the change in how inflation is measured affects real activity, slightly, through real expenditures that are indexed to the CPI. But these effects are arguably negligible for the purposes of explaining the current inflation-unemployment puzzle.

4. This raises the question of whether one should control for the traditional supply shocks of real food and energy prices and import price effects. One argument for retaining these supply shocks is that they are largely external to the U.S. economy; another is that they have been included in empirical Phillips curve specifications at least since the early 1980 s and therefore are not subject to the ex post identification bias alluded to above. Whether these arguments are compelling is a matter of judgment, but for the purposes of this discussion I retain them in my specifications. 
ductivity deviation-is unclear, so this has been omitted. Also, the sample period is different, and lagged inflation enters differently. The resulting specification is similar to that of Staiger, Watson, and I. ${ }^{5}$ The results are presented in the first column of table B1. When a constant NAIRU of 6.0 is assumed, the forecast error for the constant NAIRU, zero supply shock, dynamic forecast of GDP inflation in 1998:2 is essentially the same as that of Gordon: -2.79 versus -2.75 (that is, $1.01-3.76$ ) in table 8 . The TV-NAIRU used in table B1 is computed using the same value of $\tau_{\eta}$ as Gordon does, and the decline of inflation explained by the fall in the NAIRU, 0.63 percentage point, is close to Gordon's estimate of 0.53 percentage point. The contributions of the traditional supply shocks in tables B 1 and 8 are also similar. Evidently, Gordon's decomposition is robust to these changes in specification. Interestingly, the root mean-squared error of the dynamic simulation in table B 1 is less than Gordon's ( 0.47 versus 0.60 in table 3$)$, so the changes in the specification actually improve the performance of the Phillips curve in the mid-1990s.

This decomposition is subject to several sources of sampling uncertainty: uncertainty about the constant NAIRU through 1992; uncertainty about the TV-NAIRU and the estimate of $\tau_{\eta}$; and uncertainty about the other coefficients in the regression. The second column of table B1 illustrates the effect of the uncertainty about the constant NAIRU. For the specification described in the notes to the table, the estimated constant NAIRU is 6.3 percent. Using this value, the dynamic simulation forecast error is larger, and the amount of surprisingly low inflation explained by a drop in the TV-NAIRU approximately doubles, from 0.6 percentage point to 1.3 percentage points. A larger value of $\tau_{n}$ results in a lower estimate of the current TV-NAIRU and further increases the amount explained by a drop in the NAIRU. A proper treatment of all sources of uncertainty would, I suspect, result in a very large sampling uncertainty associated with this decomposition. This example also emphasizes the importance of the decline in the NAIRU to Gordon's story.

What can one conclude from this about the claims of proponents of the new economy? Gordon characterizes the new economy view as one in which the NAIRU has fallen. However, a more radical interpretation, 


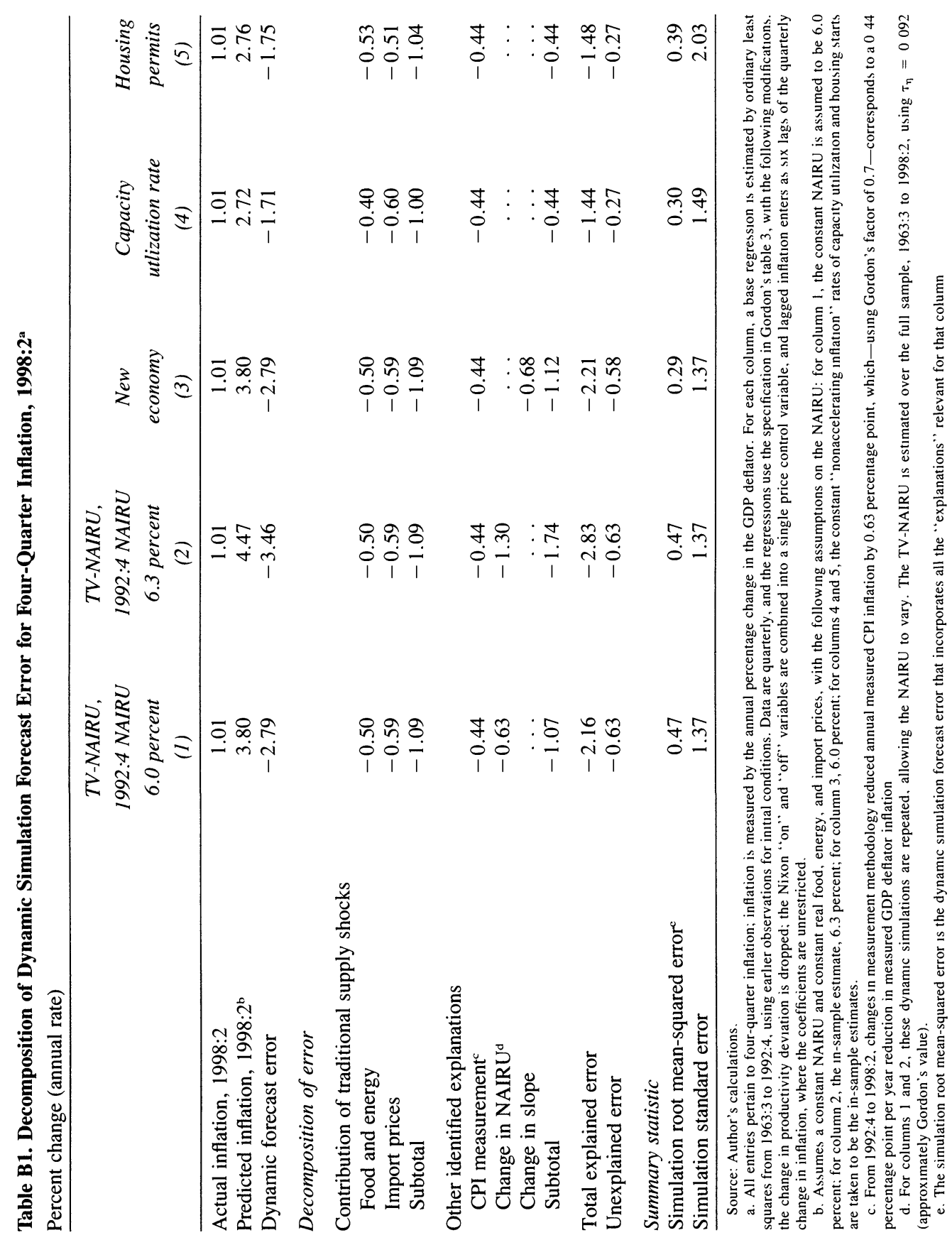


which I believe is more in keeping with new economy rhetoric, is that the traditional Phillips curve has simply ceased to be relevant. There is no longer a link between the unemployment gap and changes of inflation; according to this view, the slope coefficient in the Phillips curve is now zero. Gordon's evidence does not address this interpretation.

This hypothesis is investigated in the third column of table B1. The circa-1992 Phillips curve is estimated through 1992:4, and the dynamic simulation proceeds like that in the first column, except that from 1993 onward the slope of the Phillips curve (more precisely, the sum of coefficients on the unemployment gap) is set to zero. The results are remarkable. No fancy econometrics here: simply setting this slope to zero makes the same contribution as using a TV-NAIRU. Indeed, the simulation root mean-squared forecast error is far smaller than those in the first two columns of table B1 and in table 3.

Performing an econometric test of the stability of this coefficient involves some subtleties. It is tempting simply to test for a break in 1992:4 but this would be misleading, because 1992:4 was after all chosen by preliminary data analysis as a likely candidate for a break date. That is, the natural $t$ test has data-snooping bias. One way around this is to use a test for a break at an unknown date, such as the Quandt likelihood ratio test. Doing so yields a striking finding: the hypothesis of stability of the slope coefficient is rejected at the 5 percent level, and the break date is estimated to be 1993:1! When a regression is estimated incorporating this break date, the coefficient through 1992:4 is negative and statistically significant, but the coefficient for the post-1992 period is slightly positive and statistically insignificant.

One is therefore left with two competing interpretations of the recent unemployment-inflation experience, both of which are consistent with the data. Either the Phillips curve is stable, except for a shift in the NAIRU, or the Phillips curve is now defunct, and there is no link from the unemployment gap to changes in inflation. The implications of these two explanations are quite different, to put it mildly. But which is correct?

It is the job of a discussant to raise questions, not to answer them. Nonetheless, it is possible to provide some insights by examining other indicators of aggregate activity as predictors of inflation. Gordon looks at capacity utilization; another such indicator is housing authorizations (building permits). The fourth and fifth columns of table B1 report 
results for specifications identical to that in the first column, except that the unemployment rate is replaced by each of these indicators, respectively, and the "natural rates" of capacity utilization and housing starts are held constant at pre-1993 estimated values. The results are striking. These circa-1992 equations have the same forecast error for 1998:2after adjusting for improvements in CPI measurement and the actual paths of the traditional supply shocks, the forecast error is a mere -0.27 percentage point. Moreover, their root mean-squared forecast errors are even smaller than for the unemployment specifications that resort to a falling NAIRU and are comparable to the specification with a zero slope. These relations do not appear to exhibit a break in the early 1990s: tests for a change in the sum of the coefficients on these variables in 1993:1 are not significant at the 10 percent level when evaluated using the Quandt likelihood ratio test critical values. Finally, note that favorable supply shocks play the same role for these specifications as for the specifications based on the unemployment rate. Were it not for these favorable supply shocks, inflation today would be what it was in 1994.

I suspect that the results in the fourth and fifth columns are typical of what one would find using other proxies for activity. Recently, Mark Watson and I have examined the performance of a host of other indicators for forecasting inflation over the past two decades. ${ }^{6}$ The details of our exercise differ from the analysis here: our data are monthly, the focus is on one year ahead forecasts, and the methodology is to simulate real-time forecasting by recursively updating the estimated models. Yet the overall message is similar. During the 1990s, the unemployment rate is a poor predictor of inflation; in addition to housing starts and capacity utilization, inflation is predicted well by industrial production, employment growth (as opposed to the unemployment rate), manufacturing and trade sales, and new composite activity indexes.

All of the above suggests that the relation between inflation and many real economic indicators has been stable in the 1990s. This, in turn, constitutes evidence against the new economy view that the link between inflation and aggregate activity has been weakened or broken, and is consistent with the view that the unemployment-based Phillips curve has been stable except for a drop in the NAIRU. Thus the puzzle

6. Stock and Watson (1998a). 
is not why inflation has been so low given the unemployment rate, but rather, why the unemployment rate has been so low given inflation.

When viewed this way, the answer does not lie in an investigation of special factors that have held down price inflation, such as computers and medical prices. It suggests, instead, a closer look at labor markets and what changes, if any, have occurred in these markets in the 1990s but not elsewhere. Such factors might include the role of information technology in facilitating job searches and changes in the welfare system in the United States. These results also underscore the fact that the unemployment-based Phillips curve is but one of several tools that economists should use when forecasting inflation.

In summary, Robert Gordon has provided a simulating paper that continues his careful and important research into the relations between wages, prices, and the unemployment rate. This work emphasizes the importance of good fortune-in the guise of favorable supply shocksin explaining the current state of the U.S. economy. Significant questions remain, however, about what special features of labor markets have led to instability in forecasting relations based on the unemployment rate but not on other aggregate indicators.

General discussion: Participants discussed economic developments that could account for a downward shift in the natural rate of unemployment. Benjamin Friedman noted several changes in the labor market that Lawrence Katz has frequently emphasized. There are a million more people in prison now than ten years ago in the United States, and they are probably drawn disproportionately from the ranks of people who might otherwise be unemployed. Today, a large fraction of new jobs involve sitting at keyboards, which implies that jobs are much more flexible across companies and industries than in the past. Finally, about one out of seven job openings today is filled through temp firms. Friedman recalled that a well-functioning employment service has long been advocated as the way to reduce the natural rate and reasoned that we have gotten the benefits of an employment service, but through private temp firms rather than the public sector.

William Dickens was skeptical about the importance of some of these labor market changes, noting that the growth in the prison population did not begin in 1993 and that other changes, such as people with poor employment prospects going off welfare and into the labor force, would 
have made the current natural unemployment rate go up. Nevertheless, he thought it possible for the United States to sustain unemployment in the 4 percent range without inflation. His own bivariate vector autoregressions with prices and wages showed that price, rather than wage, innovations explained inflation, not only in the supply shock periods of the 1970s but also in the 1960s and 1980s. He speculated that firms may have planned for capacity additions on the expectation that the Federal Reserve would target the prevailing estimates of the natural unemployment rate. If capacity utilization was responsible for price pressures, the natural rate becomes a self-fulfilling prophecy. A series of favorable supply shocks have now allowed the economy to break this self-fulfilling prophecy, and capacity utilization is low enough to permit lower unemployment rates than would have been predicted from history.

William Brainard noted that the original motivation behind Phillips's idea was that unemployment is a good measure of pressure in labor markets. Since labor costs are so important, a tight labor market with rising wages would be closely associated with rising inflation. He reasoned that the whole NAIRU idea is damaged if that mechanism turns out not to be central to the inflation process. James Duesenberry suggested using wage equations that include vacancies as an explanatory variable. If wages are driven by how difficult it is to fill vacancies, a shift in the Beveridge curve in the direction of less unemployment for given vacancies would be consistent with the idea that the labor market functions more effectively today. He noted that unemployment has historically been used in price and wage equations due to the absence of reliable data on vacancies, but this procedure would miss apparently important recent labor market developments.

Edmund Phelps commented that analysis of the natural rate should make use of the rich literature on labor markets, much of it from Europe, and should employ real explanatory variables such as real prices, real policies, and institutions. He saw good evidence that the natural rate declined over the past ten years and that a sharp fall occurred in the past five years. In particular, he cited the downward trend in the proportion of the labor force who exhibit relatively high unemployment rates and the construction boom that dates from late 1993. He reasoned that the capital goods boom might have lowered the natural rate through two channels. First, it might have raised employment when it pulled up real prices in the newly attractive capital goods sector; and 
second, even after capital has shifted to that sector from the consumer goods sector, construction is relatively labor intensive.

Charles Schultze observed that because Gordon's NAIRU for wages was much higher than his NAIRU for prices, his results implied the implausible outcome that the trend labor share would increase indefinitely. He also questioned the formulation of Gordon's wage equation-in which the dependent variable is nominal wage growth minus the trend growth rate of productivity-because it assumes an immediate adjustment of wages to changes in the productivity trend. Finally, he disagreed with the paper's conclusion that the fall in inflation in the 1990 s did not overturn the natural rate framework. He thought it was more accurate to conclude that if the natural rate has consistently been a valid explanation for the relationship between inflation and unemployment, the paper provides an estimate of that rate and how it has changed over time.

George Perry pointed out that Gordon's estimated NAIRU was above the actual unemployment rate in 1962 . Given that in 1962 policymakers and economists outside the government agreed on the importance of getting the economy moving because unemployment was so high, he felt this cast serious doubt on estimates using Gordon's framework. In the alternative, Stock suggested that the experts were wrong in 1962, because they were extrapolating previous favorable experience. Brainard remarked that since the NAIRU is a smoothed two-way estimate generated via Kalman filtering, the estimated NAIRU for the 1960s is influenced by the data in the entire sample, which puts a lot of faith in the particular way Gordon has allowed change to occur. More generally, he observed that the structure behind Gordon's simple econometric framework could have changed in many ways, affecting any of the estimated coefficients: one would get a different perspective on the evolution of the economy by allowing time variation in the sum of the coefficients on unemployment or prices, rather than only in the NAIRU. And the data probably would not distinguish well among such alternative ways in which the structure might have changed.

Robert Hall recalled that in 1994 Gordon had predicted an upward jump in the rate of inflation, based on the Phillips relationship as it existed at the time. This understandable error, he noted, called attention to the fact that the Phillips equations are forecasting, not structural, relationships: there is no attempt at identification, and no structural 
interpretation can be given of the findings. For example, the estimated low forecasting power of wages for prices in Gordon's paper failed to diminish Hall's confidence that imposing a 10 percent increase in labor costs on businesses would promptly raise prices. He believed it an important finding of the paper that the joint behavior of prices, wages, unemployment, and capacity utilization has changed. This knowledge is important, even though the mechanisms behind the change are unclear. He pointed out that the paradoxical behavior of prices today is nothing new, if one takes a broader historical and cross-country perspective. Neither the collapse of U.S. prices in the 1920s nor the end of four big inflations described by Sargent could be explained by a Phillips-type relationship. He concluded that the behavior of prices has been different in different episodes and may not be predictable.

Hall also drew attention to recent theoretical models of the labor market that seem completely orthogonal to Phillips curve research. In the modern Diamond-Mortensen-Caballero framework, the wage for each job match is always at its theoretical equilibrium, and Ricardo Caballero has stressed the ability of this framework to explain variations in the natural rate of unemployment, both over time and across countries, in a way that has nothing to do with any concept of adjustment process. Being completely adjustment free, this framework is dramatically at odds with the ideas in Gordon's paper and any Phillips curve research. 


\section{References}

Franz, Wolfgang, and Robert J. Gordon. 1993. "German and American Wage and Price Dynamics: Differences and Common Themes." European Economic Review 37(4): 719-62.

Gordon, Robert J. 1971. "Inflation in Recession and Recovery." BPEA, $1: 1971,105-58$.

- 1975. "Alternative Responses of Policy to External Supply Shocks." BPEA, 1:1975, 183-206. 253-77.

1977. "Can the Inflation of the 1970s Be Explained?" BPEA, 1:1977,

. 1982. "Inflation, Flexible Exchange Rates, and the Natural Rate of Unemployment." In Workers, Jobs, and Inflation, edited by Martin N. Baily. Brookings.

— 1983. “'Credibility' vs. 'Mainstream': Two Views of the Inflation Process." In Inflation: Prospects and Remedies, Alternatives for the 1980s, edited by William D. Nordhaus. Washington: Center for National Policy.

$\longrightarrow \rightarrow$ 1984. "Supply Shocks and Monetary Policy Revisited." American Economic Review, Papers and Proceedings 74(2): 38-43.

1990. "U.S. Inflation, Labor's Share, and the Natural Rate of Unemployment." In Economics of Wage Determination, edited by Heinz König. Berlin: Springer-Verlag.

- 1994. "Inflation and Unemployment: Where is the NAIRU?'” Paper prepared for the Meeting of Academic Consultants to the Board of Governors of the Federal Reserve System. Washington, December 1.

1995. "Estimating the NAIRU as a Time-Varying Parameter." Paper prepared for the Panel of Economic Advisors to the Congressional Budget Office. (November 16).

$\longrightarrow \rightarrow$ 1997. "The Time-Varying NAIRU and Its Implications for Economic Policy." Journal of Economic Perspectives 11(1): 11-32.

Gordon, Robert J., and Stephen R. King. 1982. "The Output Cost of Disinflation in Traditional and Vector Autoregressive Models." BPEA, 1:1982, 205-42.

King, Robert G., and Mark W. Watson. 1994. "The Post-War U. S. Phillips Curve: A Revisionist Econometric History." Carnegie-Rochester Conference Series on Public Policy 41: 157-219.

Levy, Mickey D. 1997. "Slaying the NAIRU Myth," Jobs and Capital 6(Summer): 15-19.

$\rightarrow$ Phelps, Edmund S. 1978. "Commodity-Supply Shock and Full-Employment Monetary Policy." Journal of Money, Credit, and Banking 10(2): 206-21.

Seskin, Eugene P. 1998. "Annual Revision of the National Income and Product Accounts." Survey of Current Business 78(August): 7-35. 
Shimer, Robert. Forthcoming. "Why Is the U.S. Unemployment Rate So Much Lower?' In NBER Macroeconomics Annual 1998, edited by Ben S. Bernanke and Julio J. Rotemberg. MIT Press.

Sims, Christopher A. 1987. "Comment." BPEA, 1:1987, 117-20.

$\rightarrow$ Staiger, Douglas, James H. Stock, and Mark W. Watson. 1997. "The NAIRU, Unemployment, and Monetary Policy." Journal of Economic Perspectives 11(1): 33-49.

Stock, James H. 1998. "Monetary Policy in a Changing Economy: Indicators, Rules, and the Shift towards Intangible Output." Paper prepared for Bank of Japan Conference on Monetary Policy in a World of Knowledge-Based Growth, Quality Change, and Uncertain Measurement. Tokyo, June 18-19.

Stock, James H., and Mark W. Watson. 1998a. "Forecasting Inflation." Unpublished paper. Harvard University, Kennedy School of Government and the Woodrow Wilson School.

$\longrightarrow \rightarrow$. 1998b. "Median Unbiased Estimation of Coefficient Variance in a Time-Varying Parameter Model."' Journal of the American Statistical Association 93(March): 349-58.

U.S. Bureau of Labor Statistics. 1997. “The Experimental CPI Using Geometric Means (CPI-U-XG).' Unpublished paper. Department of Labor (April). 